\title{
EL TRABAJADOR DE FIN DE SEMANA EN LA SOCIEDAD DEL OCIO Tiempo de trabajo y calidad de vida en el sector servicios
}

\author{
EDUARDO BERICAT \\ Universidad de Sevilla \\ Fundación Centro de Estudios Andaluces (CENTRA)
}

\begin{abstract}
PALABRAS CLAVE ADICIONALES
ADDITIONAL KEYWORDS

Trabajo de fin de semana, Calidad de vida, Tiempo

deocio, Desigualdad social, Sociología del trabajo,

Sociología del tiempo, Sociedad posmoderna

Weekend Work, Quality of Life, Leisure Time, Social Inequality, Sociology of Work, Sociology of time, Post-modern Society.
\end{abstract}

\begin{abstract}
RESUMEN: En este artículo se exponen los resultados de una investigación cualitativa cuya finalidad era estudiar las consecuencias que el hecho de trabajar los fines de semana tiene sobre la calidad de vida de los trabajadores. El trabajo de fin de semana, a diferencia del trabajo nocturno y del trabajo por turnos, ha recibido hasta ahora muy poca atención tanto por parte de la sociología del trabajo, como por parte de los agentes políticos y sociales. El trabajo de fin de semana implica una fuerte inversión de los tiempos de trabajo y de ocio. Cuando el trabajador de fin de semana trabaja, el resto de las personas están disfrutando de su tiempo de ocio. A la inversa, cuando el trabajador dispone de tiempo libre, las demás personas están trabajando. Esta inversión o asincronia de su tiempo social explica la mayor parte de las consecuencias negativas que comporta el trabajo de fin de semana. El trabajo de fin de semana pone de manifiesto la paradoja laboral de la sociedad del ocio. En esta sociedad es imposible que todos disfrutemos simultáneamente del tiempo de ocio. La sociedad del ocio es un mito que encubre una profunda desigualdad social característica de las sociedades posmodernas.
\end{abstract}

\begin{abstract}
This article presents the results coming from a qualitative research carried out to reveal the emergent consequences that weekend work has on the life style and quality of life of workers. Until now, the sociology of work, and also political and social agents, has paid very little attention to weekend work, if any. On the contrary, there are many more studies on evenings and nights shifts. Weekend work is very relevant because it implies a radical interchange between leisure time and work time. While weekend workers are working, the rest of the people are enjoying their free or leisure time. On the contrary, when the weekend worker has his free time, the rest of the people are working. In fact, this asynchrony of his social time explains the most part of the negative consequences which come from weekend work. Weekend work reveals what we could name as the labor paradox of leisure society. In this society it is impossible that everybody enjoys free time simultaneously. Leisure society is a myth that masks a radical social inequality characteristic of postmodern societies.
\end{abstract}

E-mail: ebericat@fundacion-centra.org

Revista Internacional de Sociología (RIS)

Tercera Época, $\mathrm{N}^{\circ} 38$, Mayo-Agosto, 2004, pp. 61-99. 
R I S

REVISTA INTERNACIONAL DE SOCIOLOGÍA

№ 38, MAY0-AGOSTO, 2004

EDUARDO BERICAT

\section{INTRODUCCIÓN}

En el presente artículo se ofrecen algunos de los resultados obtenidos en una investigación social que tenía por objeto explorar las relaciones existentes entre el trabajo de fin de semana y la calidad de vida ${ }^{1}$. A este fin se estableció una estrategia de complementación metodológica entre los análisis cuantitativo y cualitativo. Para el análisis cuantitativo del trabajo de fin de semana se utilizó la Encuesta de calidad de vida en el trabajo, mientras que para el cualitativo se realizaron grupos de discusión con trabajadores de fin de semana.

El trabajo de fin de semana puede considerarse un fenómeno emergente y exclusivo de las sociedades avanzadas: es decir, de las sociedades post-industriales caracterizadas por la extensión productiva y ocupacional del sector servicios; de las sociedades del ocio, en las que la ampliación del tiempo libre ya ha configurado e institucionalizado tiempos sociales específicos; y de las sociedades de consumo, en las que una buena parte del consumo constituye un consumo de servicios realizado en los tiempos de ocio. Quizás sea la novedad del trabajo de fin de semana lo que explique la ausencia de investigaciones sobre este importante fenómeno socio-laboral, así como también el absoluto desinterés mostrado hasta ahora tanto por los agentes sociales como por los gobiernos.

Esta investigación pretende mostrar tanto la importancia cuantitativa del fenómeno, como las graves consecuencias que sobre la vida de un trabajador puede llegar a tener un régimen laboral caracterizado por el trabajo de fin de semana. Dado que las clases altas, medio-altas y medias trabajan mucho menos los fines de semana, y dado que disfrutan de su ocio con el concurso de los trabajadores de fin de semana, en su mayor parte pertenecientes a las clases medio-bajas y bajas, podría considerarse que la invisibilidad social del trabajo de fin de semana está condicionada por una estrategia clasista en la que los "privilegiados" de la sociedad del ocio no parecen estar muy interesados en percibir el malestar de los "trabajadores" de la sociedad del ocio.

En el primer apartado de este artículo se exponen con brevedad las claves teóricas que explican este nuevo fenómeno, ofreciendo al mismo tiempo información cuantitativa acerca de la extensión social y laboral del mismo. En los tres siguientes, usando tan sólo material empírico cualitativo procedente de los grupos de discusión realizados con trabajadores varones ${ }^{2}$ del sector turístico (trabaja-

\footnotetext{
1 "Adaptación y reparto del tiempo de trabajo: propuestas y alternativas para el fomento del empleo y la organización del trabajo". Grupo Investigación I+D, PB-1111. Dirección del grupo: Rosa Quesada Segura.

${ }^{2}$ La situación vital de las trabajadoras de fin de semana será el objeto de un próximo artículo. Las trabajadoras de fin de semana se enfrentan a unos dilemas diferentes, derivados del cuádruple conflicto de rol que han de soportar dada su condición social de madres, amas de casa, esposas y trabajadoras.
} 
dores seleccionados por su alta y continuada carga de trabajo de fin semana) se muestran tres aspectos básicos de las condiciones vitales que este tipo de trabajo comporta: la insatisfacción laboral y vital de estos trabajadores; las tensiones generadas por la escasez de tiempo de ocio; y la problemática de sus relaciones sociales y personales. En el apartado final, o conclusivo, se aboga por cambios en la legislación laboral que contemplen, además del "trabajo nocturno" y del "trabajo por turnos", la especificidad social y vital del tiempo de trabajo de fin de semana.

\section{LA PARADOJA LABORAL DE LA SOCIEDAD DEL OCIO}

A la sociedad moderna, caracterizada por ser una sociedad de trabajo, de ahorro y de producción industrial, le sigue la sociedad posmoderna, una sociedad de ocio, de consumo y de producción terciaria o de servicios. Ocio, consumo y servicios forman parte de un conjunto complejo de cánticos laudatorios característico de las emergentes sociedades avanzadas. Cada cántico representa la antítesis positiva de su correspondiente tesis negativa de la sociedad industrial. Así, la sociedad del ocio simboliza un cambio en la estructura del tiempo de vida, que desde ahora deja de estar exclusivamente compuesta por el binomio trabajo-sueño. Las jornadas de sol a sol se van reduciendo. Por su parte, la sociedad de consumo expresa la posibilidad de satisfacer, gracias a la elevación de los niveles de renta, un amplio y variado conjunto de deseos cada vez más distantes y ajenos a las meras necesidades fisiológicas. El binomio trabajo-pan, substrato esencial de la reproducción de la fuerza de trabajo, también deja de ser determinante. Por último, la sociedad de servicios representa condiciones de trabajo en las que no cabe la alienación típicamente industrial. Las ocupaciones de servicios (cuello blanco), que habían sido metas de movilidad vertical, se extienden. El binomio trabajo-máquina (cuello azul) pierde su hegemonía en la nueva sociedad de ocupaciones terciarias.

Ahora bien, pese a sus evidentes bondades, las sociedades avanzadas no están exentas, como cualquier otro tipo de sociedad, de sus propias contradicciones. Así, la confluencia de mayor tiempo libre o de ocio, el incremento de los niveles de consumo y la importancia que el consumo de servicios adquiere en los tiempos de ocio, sientan las bases de una ineludible paradoja. Esta paradoja surge de una simple peculiaridad temporal del sector servicios que, como veremos, tiene importantes consecuencias sociales. A diferencia de la producción industrial, en la que la materialidad de los bienes hace posible que los tiempos de producción sean independientes de los tiempos de consumo, el sector servicios se caracteriza por la coincidencia espacio-temporal de producción y consumo (Bericat, 1999). En una gran parte de los servicios el productor y el consumidor, esto es, el trabajador y el cliente, deben estar en el mismo espacio y en el mismo tiempo. El socorrista de una piscina, el vendedor de un comercio, el camarero de un bar, 
RIS

REVISTA INTERNACIONAL DE SOCIOLOGIA

№ 38, MAYO-AGOSTO, 2004

el actor de teatro, el taxista, el médico, el guardia de seguridad, etc., no puede producir su servicio sin que esté presente el bañista, el comprador, el cliente, el espectador, el viajero, el enfermo, etc.. Sin duda, en algunos casos puede conservarse el servicio mediante su materialización en producto, como así sucede en la producción cinematográfica. Pero esto no siempre es posible. El acomodador de un cine sólo puede prestar su servicio en el preciso momento y lugar en que las personas entran en la sala de proyección.

En términos generales, por tanto, podemos afirmar que en todos los sectores económicos basados en la prestación de servicios, y vinculados al consumo de tiempo de ocio, estará presente la paradoja laboral de la sociedad del ocio, paradoja que puede expresarse en los siguientes términos: cuando unas personas estén disfrutando de su tiempo de ocio, otras personas habrán necesariamente de estar trabajando. El principal problema de esta paradoja estriba en que cuanto mayor sea el tiempo de ocio y cuantas más personas puedan disfrutarlo, mayor número de personas habrán de estar trabajando en esos mismos tiempos. Y el dilema fundamental de la sociedad del ocio, por tanto, podría expresarse como sigue: En el seno de una sociedad, es temporalmente imposible que todos sus miembros disfruten del ocio al mismo tiempo. En suma, riesgos de dualización social: "tiempo de ocio de unos, trabajo en tiempo de ocio de otros". Es decir, mientras y para que unos puedan divertirse, otros tendrán que estar trabajando.

Esta paradoja laboral, constituida por la necesaria sincronización consuntivoproductiva de los tiempos de ocio y de trabajo, señala un fenómeno radicalmente nuevo y exclusivo de las sociedades posmodernas, sociedades de ocio, de consumo y de servicios. Ahora bien, podríamos preguntarnos: ¿tiene consecuencias sociales el hecho de que mientras unos disfrutan de sus tiempos de ocio otros tengan que trabajar para ellos? La respuesta a este interrogante depende del concepto de tiempo que utilicemos. Si concebimos el tiempo como una magnitud abstracta, mecánica, uniforme y cuantitativa, cuarenta horas semanales de trabajo, independientemente de cuándo trabajemos esas horas, serán exactamente cuarenta horas de trabajo. Sin embargo, desde una concepción social del tiempo, desde una adecuada sociología del tiempo que atienda tanto a la sincronización social como al sentido social del tiempo, el tiempo aparece cargado de múltiples cualidades y valencias. El tiempo social no constituye en ningún caso un flujo indiferenciado, sino que demarca y determina en cada momento y lugar una específica trama de interactividades funcionales y de valores simbólicos asociados. Durkheim, Sorokin y Merton, Cassirer, Elias, Zerubavel, Lewis y Weigert, Nowotny, Mark, entre otros muchos autores, han puesto de manifiesto en sus trabajos la naturaleza social del tiempo.

La clave que determina y explica la mayor parte de las consecuencias vitales asociadas con la paradoja laboral de la sociedad del ocio es, precisamente, la inversión de los tiempos de trabajo y de ocio que sufren este tipo de trabajadores. Analizando la estructura temporal del sector de servicios turísticos y de ocio, 
que constituye a este respecto el caso paradigmático, podemos ver cómo la triple estacionalidad que le afecta (diaria, semanal y anual), determina otras tantas inversiones en el tiempo social de sus trabajadores. La carga de trabajo en este sector se incrementa durante las horas del día en las que la mayor parte de las personas están fuera del trabajo. Del mismo modo, su carga de trabajo se incrementa durante los fines de semana. Por último, también se incrementa la carga en los períodos vacacionales del año, esto es, puentes festivos, Semana Santa, Navidades y meses de vacaciones. En suma, este tipo de trabajadores viven en el seno de la estructura temporal de la sociedad con el paso cambiado. Cuando los demás disfrutan de su tiempo libre, ellos están trabajando; cuando los demás están trabajando, ellos disfrutan de su tiempo libre. La pregunta clave, a este respecto, es si se puede disfrutar de la misma manera y en idéntico grado del tiempo libre cuando la sociedad, en general, está trabajando. A la inversa, si trabajar cuando los demás disfrutan de su tiempo libre comporta algunas consecuencias negativas sobre la vida de los trabajadores más allá de las que puedan derivarse de las condiciones laborales intrínsecas de un determinado puesto de trabajo.

Los resultados de la investigación cualitativa nos ofrecen, desde la perspectiva de los propios trabajadores de fin de semana, una respuesta contundente a ambas cuestiones. Debido exclusivamente a la inversión de los tiempos de trabajo y de ocio, el trabajo de fin de semana determina un evidente deterioro de la calidad de vida de estos trabajadores. Siendo esto así, la magnitud social del problema al que nos enfrentamos depende de su extensión. Si el problema, aún siendo grave, afectara a pocos o muy pocos trabajadores reclamaría una solución particular y una consideración específica. Pero si comprobamos que afecta a una buena parte de la población ocupada, el fenómeno adquiere el rango de problema estructural. Las soluciones, en este caso, resultan ser mucho más complejas, pues nos encontramos ante consecuencias indeseadas que derivan de rasgos esenciales de nuestras sociedades avanzadas, sociedades posmodernas constituidas intimamente por el incremento del tiempo de ocio y por el constante aumento del consumo de servicios realizado durante ese tiempo.

En el cuestionario de la Encuesta de calidad de vida en el trabajo se incluye la siguiente pregunta: "En las cuatro últimas semanas y en el empleo que nos estamos refiriendo, ¿trabajó algún sábado y/o algún domingo?”. Pregunta con cuatro posibles respuestas: "1. No", "2. Algún sábado", "3. Algún domingo", y "4. Algún sábado y algún domingo". Los porcentajes de "trabajo de fin de semana", que aparecen en la tabla 1, corresponden a la suma de las respuestas 2,3 , y 4 . Incluyen, por tanto, a las personas que han trabajado sólo algún/os sábado/s del mes, algún/os domingo/s del mes, o algún/os sábado/s y domingo/s. Los porcentajes de "trabajo de sábados y domingos" corresponden tan sólo a la respuesta 4. Este último concepto es mucho más restrictivo, e implica que el ocupado trabajó al menos un sábado "y" un domingo al mes, es decir, en general estos ocupados trabajaron al menos un fin de semana completo. Según los datos ofrecidos por esta 
R IS

REVISTA INTERNACIONAL DE SOCIOLOGIA

№ 38, MAYO-ACOSTO, 2004

EDUARDO BERICAT

fuente, cuyo trabajo de campo se llevó a cabo en junio de 1999, el porcentaje de población ocupada que ha trabajado al menos algún sábado o domingo durante el último mes ("trabajo de fin de semana") alcanza la cifra del $54,8 \%$, esto es, más de la mitad de la población ocupada española. Asimismo, el porcentaje de ocupados que al menos trabajaron durante el último mes un fin de semana completo asciende al 26,1 \%, esto es, uno de cada cuatro trabajadores españoles trabaja al menos un fin de semana completo al mes. El número total de españoles afectados por el trabajo de fin de semana asciende, respectivamente, a 7,5 y a 3,6 millones de ocupados, datos que por sí mismo dan cuenta de la extensión del fenómeno.

Tabla 1.

Distribución por sectores y ramas del trabajo de fin de semana (\% columna), $y$ proporción de trabajo de fin de semana por sectores y ramas (\% fila).

\begin{tabular}{|c|c|c|c|c|}
\hline \multirow[b]{2}{*}{ RAMAS DE ACTIVIDAD } & \multicolumn{2}{|c|}{ Trabaja "fin de semana" } & \multicolumn{2}{|c|}{ Trabaja "sábados y domingos" } \\
\hline & $\%$ columna & $\%$ fila & $\%$ columna & $\%$ fila \\
\hline Sector Primario & 9,0 & 74,3 & 10,7 & 42,1 \\
\hline Agricultura, ganadería & 8,1 & 76,3 & 9,8 & 44,0 \\
\hline Pesca, acuicultura & 0,9 & 59,7 & 0,9 & 29,0 \\
\hline Sector Secundario & 23,6 & 42,9 & 16,3 & 14,1 \\
\hline Extracción minerales & 0,2 & 57,1 & 0,1 & 12,4 \\
\hline Industria alimentos, bebidas & 2,8 & 49,8 & 1,7 & 14,6 \\
\hline Fabricación caucho, plásticos & 0,4 & 62,6 & 0,3 & 22,5 \\
\hline Construcción & 7,3 & 40,0 & 4,2 & 10,8 \\
\hline Sector Terciario & 66,2 & 58,8 & 72,0 & 30,4 \\
\hline Venta vehículos, combustible & 2,6 & 54,9 & 1,5 & 14,7 \\
\hline Comercio por menor & 14,2 & 77,6 & 9,1 & 23,7 \\
\hline Hostelería & 13,1 & 90,5 & 21,5 & 70,5 \\
\hline Transporte terrestre & 3,4 & 69,7 & 3,5 & 33,5 \\
\hline Transporte marítimo & 0,6 & 79,0 & 0,9 & 53,9 \\
\hline Transporte aéreo & 0,2 & 64,1 & 0,4 & 64,1 \\
\hline Agen. viajes, comunicaciones & 2,9 & 55,9 & 2,7 & 24,5 \\
\hline Otras actividades empresarial. & 2,7 & 57,0 & 2,6 & 25,9 \\
\hline Admón. Públicas, Seguridad & 6,1 & 41,5 & 8,5 & 27,4 \\
\hline Educación & 2,0 & 21,1 & 2,6 & 13,1 \\
\hline Sanidad. Serv. Sociales & 5,1 & 70.2 & 7,4 & 48,6 \\
\hline Saneamiento público & 2,8 & 49,4 & 2,3 & 19,6 \\
\hline Act. recreativas, culturales & 3,9 & 59,3 & 2,3 & 41,8 \\
\hline Servicios personales. & 1,3 & 63,8 & 3,5 & 27,0 \\
\hline
\end{tabular}

Fuente: ECVT-99. Elaboración propia.

66 
En la tabla 1 puede verse cómo se distribuye el trabajo de fin de semana según sectores económicos y ramas de actividad. Según los porcentajes de columna de este cuadro, un 9,0\% del total de "trabajadores de fin de semana" está ocupado en la agricultura, un $23,6 \%$ en la industria y un $66,2 \%$ en los servicios. Por otra parte, un $10,7 \%$ del total de "trabajadores de sábados y domingos" está ocupado en la agricultura, un $16,3 \%$ en la industria y un $72,0 \%$ en los servicios. Estos datos muestran, sin ningún género de dudas, la terciarización del trabajo de fin de semana. Dado que el sector servicios ocupa a más población, también interesa conocer los porcentajes relativos de trabajo de fin de semana en cada uno de los sectores (porcentajes de fila en la tabla). Allí se comprueba que el sector más afectado por el "trabajo de fin de semana" y por el "trabajo de sábados y domingos" es el sector primario $(74,3 \%$ y $42,1 \%$, respectivamente), seguido del sector servicios $(58,8 \%$ y $30,4 \%)$ y, por último, del sector industrial $(42,9 \%$ y $14,1 \%)$.

$\mathrm{Al}$ objeto de formarnos una idea más exacta y detallada de la estructura productiva del trabajo de fin de semana, interesa conocer tanto la distribución como la proporción de ocupados de fin de semana según ramas de actividad. El análisis se ha realizado según una clasificación de cuarenta y cuatro ramas ${ }^{3}$, si bien en el Cuadro 1 sólo se incluyen aquéllas que destacan en alguno de los datos analizados. Las ramas de actividad que ocupan a más trabajadores de "fines de semana" son el comercio al por menor $(14,2 \%)$, la hostelería $(13,1 \%)$, la agricultura $(8,1 \%)$, la construcción $(7,3 \%)$, la seguridad $(6,1 \%)$, la sanidad $(5,1 \%)$, el conjunto de ramas del transporte y actividades anexas a él (total de 7,1\%), y las actividades recreativas y culturales $(3,9 \%)$. En la distribución de personas que trabajan "sábados y domingos", la rama de hostelería ocupa a más de uno de cada cinco trabajadores $(21,5 \%)$, siendo importantes también la agricultura $(9,8 \%)$, el comercio al por menor $(9,1 \%)$, la seguridad $(8,5 \%)$, la sanidad $(7,4 \%)$, y el conjunto de ramas del transporte (total de 7,5\%). Es de reseñar que, de un total de 22 ramas industriales incluidas en la clasificación, solamente 3 se han incluido en la tabla 1. En suma, seis ramas de actividad (hostelería, agricultura, comercio, seguridad, sanidad y transporte) ocupan a 2 de cada 3 "trabajadores de sábados y domingos" $(63,8 \%)$.

Demostrada la amplia extensión social del fenómeno, mostraremos en los epígrafes restantes el tipo de consecuencias que sobre la experiencia vital de una persona tiene la inversión de tiempos de trabajo y de ocio, inversión a la que están sometidos típicamente los trabajadores de fin de semana. Sin embargo, antes de entrar en el contenido del discurso, interesa hacer algunas precisiones metodológi-

\footnotetext{
${ }^{3}$ Esta clasificación de 44 ramas, basada en la Clasificación Nacional de la Actividad Económica de 1993 (C.N.A.E.-93), es la utilizada habitualmente en diversas estadísticas laborales (ver, por ejemplo, la publicación Anuario de estadisticas laborales y de asuntos sociales).
} 
RIS

REVISTA INTERNACIONAL DE SOCIOLOCIA

№ 38, MAYO-ACOSTO, 2004

EDUARDO BERICAT

cas sobre la composición de los grupos ${ }^{4}$. Todos los participantes son trabajadores varones de entre 16 y 50 años, por lo que el discurso que se sintetiza es puramente masculino. Todos ellos son trabajadores turísticos, esto es, camareros, recepcionistas, cocineros, socorristas, trabajadores del aeropuerto, de mantenimiento, de hoteles, discotecas, etc.. Todos estaban trabajando al menos tres de cuatro fines de semana al mes, y habían trabajado en este régimen temporal al menos durante dos años. Es decir, son personas con una situación laboral definida por un grado intenso de inversión temporal trabajo-ocio, y que cuentan con una experiencia suficiente sobre las consecuencias de tal inversión. Por último, en general, son trabajadores de bajo estatus laboral y personas de bajo estatus social.

La síntesis del discurso sobre su calidad de vida se ha realizado en el marco de interacción de tres ámbitos claves de su modo de vida. Primero, la estructura temporal del trabajo, impuesta por las condiciones productivas del sector y por las determinaciones organizativas de las empresas. Segundo, la gestión del tiempo libre que realizan los propios trabajadores para acoplar el tiempo de vida al tiempo de trabajo. Y tercero, las consecuencias relacionales de la inversión de tiempos, en tanto que afectan sobre todo a novias, mujeres y amigos.

\section{LA ESTRUCTURA TEMPORAL DEL TRABAJO DE FIN DE SEMANA Y LA CALIDAD DE VIDA}

Sennet y Cobb, en el capítulo quinto de su libro The Hidden Injuries of Class, ofrecen una explicación al hecho de que unas ocupaciones estén más valoradas que otras en términos de estatus o prestigio social, valoración que es independiente tanto de su poder económico como de su poder politico. Los autores pretendían explicar por qué algunas ocupaciones de servicios predominan en el fondo de las escalas de prestigio ocupacional. Pese a lo que algunos creen, no son las ocupaciones industriales las que tienen un menor prestigio. Este hecho sorprende porque los "profesionales", que son también ocupaciones de servicios, aparecen siempre en la cima de esas mismas escalas de prestigio ocupacional. Para Sennet y Cobb, el conocimiento, esto es, el saber experto y exclusivo que controla el profesional, le otorga una gran independencia. Impide que los demás, por ejemplo clientes y jefes, puedan decirle a él qué es lo que tiene que hacer. En

\footnotetext{
${ }^{4}$ Los grupos se realizaron en Marbella y Torremolinos. Se utilizaron guías de entrevista con muy bajo nivel de estructuración, orientadas en un grupo por el estímulo temático de las "condiciones de trabajo", y en el otro por el de "tiempo libre". Estos dos grupos forman parte de una investigación más amplia, que incluye grupos con mujeres trabajadoras de fin de semana, grupos de cónyuges de trabajadores y trabajadoras de fin de semana, y grupos de hijos de trabajadores y trabajadoras de fin de semana.
} 
esta situación, persona y trabajo coinciden en el marco de una libertad donde amor y poder son compatibles, máxima expresión de la libertad según Nietzsche. "Sólo de ti depende; si eres buena persona podrás ser un buen doctor". Por este motivo, "las ocupaciones en las que el individuo posee cierto grado de autonomía - esto es, cierto grado de libertad respecto de la autoridad y respecto de la definición de sus funciones en términos de las cambiantes demandas de los demás-son más deseables que las ocupaciones en las que la persona tiene que tratar con los demás y responder a sus cambiantes demandas" (Sennet y Cobb, 1972: 235-236). Así se explica, por ejemplo, que el camarero tenga un nivel de prestigio inferior al minero, ocupación paradigma de la primera Revolución Industrial. O que el del taxista sea inferior al del camionero. De hecho, si consultamos el fondo de cualquier escala de prestigio (Carabaña y Gómez, 1996), encontraremos un cúmulo de ocupaciones de servicios, entre las que se encuentran los camareros, desempeñando su trabajo frente a otros (clientes) y a merced de las órdenes de los otros (jefes y clientes). Así sucede, también, con otras ocupaciones de la hostelería y de los servicios turísticos en general, ocupaciones que constituyen el objeto de nuestra investigación cualitativa.

De acuerdo con las previsiones de Sennet y Cobb, y al margen de los comentarios salariales que obviamente se suscitaron en los grupos, y en los que no entraremos, los trabajadores son bien conscientes de que sus condiciones de trabajo están determinadas por dos factores: uno, su incapacidad para controlar el tiempo, y dos, su dependencia del público. El primero, como podrá verse en sus propias manifestaciones, está vinculado a un determinado régimen de horarios laborales. El segundo, por el contrario, deriva del necesario trabajo emocional al que se ven sometidos, por trabajar "cara al público", en trato con las personas a las que sirven, personas que ostentan un estatus superior frente a ellos. En suma, su trabajo se desarrolla en el marco de una doble relación personal dependiente y subordinada: intensa dependencia y subordinación personal con respecto al jefe, por un lado, y con respecto al cliente, por otro. El jefe, o el encargado, es la expresión personal de las constricciones horarias; el cliente es la expresión personal de su servidumbre socials.

[1] - Bueno, pues a mí lo que ya ha dicho el compañero, de esto de no tener posibilidades de descansar ni sábados, ni domingos, pero vamos, el verano es lo nuestro, que es el turismo y hay que aguantar, agachar la cabeza y tirar para alante. Entonces se descansa los dias entre semana, no coincides con tu chica, tal y cual, pero es lo que hay que hacer, el turismo es nuestro trabajo. Después yo he pensado también, los clientes, hombre, estoy de cara al público y siempre estoy con clientes. Hay algún

\footnotetext{
${ }^{5}$ Todas las cursivas que aparecen en las transcripciones de los grupos de discusión son, como es obvio, nuestras. Estas cursivas subrayan elementos clave del discurso de estos trabajadores.
} 
RIS

REVISTA INTERNACIONAL DE SOCIOLOCIA

№ 38, MAYO-AGOSTO, 2004

EDUARDO BERICAT

cliente agradable, otros que no son tan agradables y hay que sonreir y hay que ser amable, y eso es lo que yo pienso. (15:06)

[2] - El que trabaja un fin de semana acaba agotadito, agotado fisica y psíquicamente al cabo del tiempo, porque es que te cambia muchos hábitos. No sé yo la juventud eso. Yo estaba esperando a que llegara el viernes. Yo he llegado un punto en que yo odiaba, yo decía a mi novia yo es que yo odio el fin de semana, es que no me gusta, es que yo veo un viernes, un sábado o un domingo y me pongo malo, me pongo malo. (15: 15)

[3] - Y el convivir, el convivir es más dificil también. Si tú trabajas con ese ritmo y tu compañera, tu mujer que está ahí conviviendo tiene el ritmo, el más común, porque nosotros somos digamos un poco la excepción. Es más difícil que se acostumbre la gente a nuestro ritmo de trabajo que nosotros acostumbrarnos a la mayoría. La gente que trabaja de lunes a viernes, con su horario, de mañana, tarde, ... está mucho más organizado que nosotros, los que trabajamos los fines de semana ... Pero si al mismo tiempo tu pareja, tú estás con un ritmo de vida y ella está con el ritmo de vida distinto, el contrario, como yo le digo siempre ... (15: 40)

[4] - Es un tema de servicio al de fuera, y claro, es una cosa muy bonita, porque tú en una discoteca, tú en un bar, otro en una recepción, todos damos servicio a los demás, pero llega un momento en que a nosotros también nos gustaria que nos dieran ese servicio, y cuando eres joven, vosotros sois más jóvenes, pues se echa en falta, y a medida que te haces mayor te lo tomas más tranquilo, ya es lo que has dicho tú, llegar a casa y estar tranquilo, y...

- Ya, pero la mujer...

- La mujer, el problema es la mujer. En ese servicio que tenemos los que llevamos en hostelería o en turismo, cuando estás casado ese es el problema. (16.108)

Un cierto sentimiento de humillación es evidente cuando se refieren a la necesidad de "agachar la cabeza y tirar para alante", así como cuando dicen que "hay que sonreír y ser amable". También señalan, desde un principio, importantes efectos derivados de la inversión de tiempos que produce el trabajo de fin de semana. Cambia muchos hábitos; resulta más difícil organizar la vida; acabas agotado física y psíquicamente, resulta más difícil la convivencia con otras personas, y en particular con la novia, la mujer y los amigos; y crea evidentes problemas con la pareja, "la mujer, el problema es la mujer". La inversión del tiempo no es meramente una mutación del tiempo social o habitual de las personas, como cuando afirman que "se descansa los días entre semana". Constituye también una verdadera mutación personal, vital y emocional, "yo es que yo odio el fin de semana". La inversión temporal, por otra parte, viene a ser reflejo de una especie de anormalidad social marcada por un ritmo de vida no sólo distinto, sino contrario al "más común", 
porque estos trabajadores se consideran "un poco la excepción", y por esto es a ellos a quienes se exige el necesario esfuerzo de adaptación. Inversión de tiempos asociada en último lugar, pero no por ello menos importante, a una inversión social que produce sentimientos agridulces respecto al trabajo. Servir a las demás personas, dicen con orgullo, "es una cosa muy bonita". Pero enseguida asalta una lánguida tristeza al reconocer que "llega un momento en que a nosotros también nos gustaría que nos dieran ese servicio". Sentimiento paralelo a una falta de correspondencia en el intercambio social que afecta, habitualmente, a las personas que ocupan posiciones bajas en la estratificación de la sociedad. Subordinación produtivo-laboral (jefe), y subordinación produtivo-consuntiva (cliente).

Jefes:

[5] $-¿$ Condiciones? Bueno, pues que mi jefe es un poquito negrero.

- (Risas de todo el grupo)

- ¡Vaya hombre! (15:5)

[6] - El problema es que siempre tienes veinticinco mil puestos encima.

- Por muy bien que se porte el jefe siempre hay algo que hablar de él. Y si no es del jefe es del encargado ...

- Si lleváis tiempo, bueno, llevamos tiempo en hostelería. Si el jefe es bueno el encargado que tiene es ...

- Un hijoputa.

- ... si el encargado es un hijo de puta el jefe es un buenazo. Tiene que ser compaginado. (16:150)

[7] - Y ese es el tipo de gente que tenemos aquí en hostelería...

- (Hablan todos a la vez) $(16: 92)$

\section{Clientes:}

[8] - Después cuando estuve en el McDonalds lo que menos me gustaba era la sonrisa falsa. Es que no me gusta. Cuando yo tengo un día malo, tengo un día malo, pero me obligaban a tener una sonrisa en la cara porque como estaba la mayor parte del tiempo cara al público y esa empresa pues tiene como una especie de no sé, ahí tenemos que ser todos muy simpáticos y muy agradables. Y nada, la primera bulla que me habían echado por estar normal. Tenía que estar con la sonrisa en la cara y si a mí no me apetece reír no me río. Tenía que saludar y reírme y ... la gracia y si alguien te trataba de malas maneras tenías que tratarlo con más simpatía todavía y eso a mí no me gustaba. Si una persona te trata mal yo no la voy a tratar mal, pero tampoco me tengo que reír, sonreírle, ni ser agradable, ni nada de eso. Y eso es lo que ... (15: 11) 
[9] - Es que hay que mirarlo de esta forma, de que tú eres el frente, para ti..., tú eres el representante de aquel restaurante, aquella discoteca y tienen que soltar lo que les haya pasado, cualquier pequeñez que les haya pasado pues la descargan contigo ... (16.49)

- Para trabajar de cara al público hay que tragar mucho también, ¿eh? La gente..., sobre todo... (16: 10)

- El problema no es cuando alguien tiene un problema y te lo dice, porque para eso eres profesional, el problema es cuando ya empiezan a faltar al respeto (16: 50)

[10]- Hasta que no se va el último invitado del banquete tienes que estar ahí aunque solamente saquen una copa más, pero tiene que estar todo limpio y tiene que estar todo ... mañana a las siete de la mañana, las siete de la mañana. (15: 56)

- Yo nuestra hora de comida siempre ha sido hasta que el restaurante no haya nadie y solo después comemos nosotros. (15: 57)

Veinticinco mil puestos por encima, o fondo de la jerarquía laboral. Relaciones siempre conflictivas con el jefe, con el encargado o con quién sea. Ellos saben así de su sometimiento estructural. Quién sea el que pone la "mala cara", quién sea el "negrero", constituye un mero accidente. Siempre estará compaginado. $\mathrm{Y}$ es que en su trabajo hay que "tragar mucho". Son el "frente" de la empresa, el mismo frente del que habla Goffman en La presentación de la persona en la vida cotidiana, pero "frente", no al servicio de la hipocresía y de los intereses personales de la clase media americana, sino "frente" como recurso laboral exigido por y para el servicio económico de la empresa. El empleado de McDonalds expresa perfectamente la tesis del "trabajo emocional" (emotion work) teorizado por Hochschild. La sonrisa en el trabajo no corresponde, al igual que sucede en la vida privada, a un auténtico sentimiento interior de la persona. Constituye un recurso productivo del empleado de los servicios que trabaja cara al público. Estás a merced del cliente; por eso hay que tragar, tragar incluso las faltas de respeto. Sabes que eres el último en la jerarquía laboral, y que no significas nada en comparación con el consumidor. Hablando de tiempos, no te vas hasta que no se va el último invitado, aunque sólo sea por una copa más. No comes hasta que en el restaurante no haya nadie; después de nadie comes tú.

Las presiones que el jefe ejerce sobre los trabajadores de la hostelería derivan en gran parte, como veremos a continuación, de la estructura del horario laboral. Lo que hasta ahora hemos visto es el sentimiento de alienación del trabajador, sentimiento que crece en la medida que los horarios son más extraños o "anormales", en la medida que resultan más incompatibles con la organización de un modo de vida normal. La personalización de estos imperativos en los jefes hace que los sentimientos de autonomía, libertad y dignidad decrezcan, y de ahí la propensión en estos sectores de actividad a organizarse mediante la figura del "trabajador autónomo". Sus horarios siguen siendo tan anormales como los de los 
trabajadores por cuenta ajena, pero al menos evitan sentir el peso de la jerarquía laboral y se sienten libres de los yugos personales. Sienten que trabajan mucho, pero al menos trabajan "para ellos", al menos son ellos, y no otras personas, quienes al final del día se llevan la "caja".

La estructura temporal en la hostelería no se caracteriza por la mera inversión de tiempo de trabajo y ocio, esto es, porque tengan que trabajar sábados y domingos, y descansar los martes o los miércoles. Es una estructura más compleja, llena de matices, en la que la organización del tiempo de trabajo y del tiempo libre, como ponen de manifiesto los participantes de los grupos de discusión, presenta matices muy importantes.

[11] - Y al principio te gusta (trabajar sólo los fines de semana), pero cuando llevas cinco años estás loco por disfrutar un sábado, estás loco ... vamos, que estäs loco porque te venga otro trabajo como una persona normal y quieres divertirte cuando se divierten las personas. Es decir, eso al principio me daba igual, ¿no?, qué divertido, tengo todos los días libres y tal, pero al final ... (15-7)

[12] - Este (el jefe) dice descaradamente en tu cara: "tú tienes dos días y medio de vacaciones pagadas por mes trabajado, o sea, 30 días de vacaciones al año, un día de descanso a la semana, ah, pero julio y agosto olvidate del día descanso", y te lo dice asi en tu cara, y un mínimo de 10 horas al día. (16:89)

- En verano, a partir de julio, el trabajo desde el 1 de julio hasta el 31 de agosto, hasta el 15 de septiembre, pero sin ningún día de descanso, o sea, yo no tengo ningún momento de ocio en ese verano (16:18)

[13] - Por ejemplo el que descanses un día un lunes y a la semana siguiente descanses un domingo son catorce dias que hay por medio de trabajar sin descansar, que descanso un día a la semana, un día te toca un lunes y otro día te toca un domingo. Sí, pero claro, no se da cuenta de que hay dos semanas de por medio de días trabajando. Pero también eso quema mucho a la persona que trabaja, son catorce días seguidos o doce o diez. (15.46)

[14] - Pues yo por ejemplo no tengo un dia de descanso fijado durante la semana, o sea, pues un lunes, un martes, un miércoles, un domingo, un sábado (15-1)

- Tengo dos días pero no juntos, descanso dos días separados en la semana, que eso es otro mundo.

- Yo descanso un día, que legalmente son dos. Yo descanso uno nada más. (15:120)

[15] - Mira, yo dentro de los horarios casi me puedo considerar un poco medio privilegiado en lo que es cantidad de horas; normalmente tengo 40 horas semanales, casi siempre, lo que ocurre que eso, que una semana me toca por la tarde, a lo mejor otra semana me toca por la mañana, o me toca de noche...(16:57) 
- Y cara el público quema, es un trabajo que quema mucho y turnos cambiados, de mañana, de tarde, de noche, la comida, pues un día comes a la una, otro día comes a las cinco y al día siguiente comes a las siete de la tarde. Eso quema mucho ... (15: 12)

[16] - me llego a la una y media que sale (su amigo) de allí, de Boccatta, que está trabajando allí en Puerta Blanca, y nos damos una vueltecita; eso es..., pero vamos ya reventados, sin ánimos, un martes, todos muertos..., no es lo mismo un sábado todo vivo a un martes todo muerto, que pareces dos borrachos a las cuatro de la mañana en la calle, no es lo mismo que... ni hay niñas ni nada que mirar. (15:100)

[17] - ¿hay muchos sitios en los que se trabaja cinco días, con sus 40 horas?.

- ¿En los hoteles?

- En los hoteles de prestigio, después de mucha lucha. (16:86)

De este conjunto de extractos emerge una serie de conceptos clave que definen la estructura del tiempo de trabajo y del tiempo libre en relación a los modos de vida: 1) cantidad; 2) frecuencia; 3) duración; 4) continuidad; 5) regularidad; 6) previsibilidad; y 7) localización. La cantidad de tiempo, por ejemplo, del tiempo libre en un determinado período es el producto de la frecuencia con que se disponen tiempos libres en ese periodo y de la duración de esos tiempos. Las preguntas a responder son "cuánto" tiempo libre y "cada cuánto". Hace cuánto tiempo que no disfrutas de un sábado, por ejemplo, parece constituir un hecho de vida fundamental. El ritmo normal es disfrutar de un sábado cada semana. Cuántos años llevas sin disfrutar un sábado parece así mismo otro hecho fundamental, también quema. La "continuidad" hace referencia al hecho de si se interrumpe o no el tiempo libre del que dispone el trabajador en un período determinado, por ejemplo semanal o anual. Tener dos días de fiesta a la semana, pero no juntos, tiene sus efectos. Teniendo dos días, el primero puede servir de descanso, mientras que el segundo puede ser utilizado para el ocio activo. Teniendo dos días, también se amplía la posibilidad de realizar actividades que requieren períodos de tiempo más largos, por ejemplo un viaje. Otro elemento fundamental es la "regularidad" con que se disfruta el tiempo libre, regularidad que permite mayores grados de habituación en el modo de vida, así como mejoras en la organización personal del tiempo. Está demostrado que somos seres rítmicos, así como los perjudiciales efectos que tienen los "turnos de trabajo" sobre la calidad de vida. Con todo, una irregularidad del tiempo libre no es todavía el caso más desfavorable, pues a la irregularidad puede agregarse la "imprevisibilidad". Los tiempos pueden ser irregulares e imprevisibles, lo que constituye, como veremos más adelante, el colmo de la desorganización y el colmo del malestar. Constituye el caso límite en el que ningún plan de vida es posible. Por último, "cuándo" tienes posibilidad de disfrutar tu tiempo de ocio, es decir, su localización, afecta de lleno al valor 
social del tiempo, al tiempo social, y al problema de la inversión de tiempo. "No es lo mismo" poder salir con tu amigo, aún menos con tu novia o con tu mujer, un "martes todo muerto" a un "sábado todo vivo". Idéntica conducta, por ejemplo, tomarse unas copas, adquiere un significado social radicalmente distinto. Si un joven bebe el sábado, se dice de él que iba "muy animado", si bebe un martes, sin duda parecerá un "borracho".

Más allá de esta clarificación analítica, de estos extractos nos queda la impresión general de que en la hostelería la desregulación y la flexibilidad del tiempo de trabajo es máxima. Nos queda la impresión de que son normales todas las condiciones desfavorables imaginables en términos de cada uno de los siete conceptos estructurales esbozados. Un trabajador que trabaja 40 horas semanales se considera "privilegiado", lo cual indica la cultura normativa del tiempo en este sector. Diez horas diarias tampoco parece ser una cantidad de tiempo excepcional. Pero en este sector sólo cabe considerarse "medio privilegiado", pues si la cantidad total es la normal, otras anormalidades, como los turnos o el variable horario de las comidas, siempre parecen estar presentes. Privilegiados, con todo, ni en los hoteles, en los que las organizaciones de trabajadores pueden contar con un mayor poder laboral. Sólo en los hoteles de prestigio, y sólo después de mucha lucha. Ahora puede entenderse por qué el jefe, o en su defecto el encargado, reciben esa animadversión tan explícita por parte de los trabajadores, sometidos a una estructura del tiempo de trabajo que les incapacita para disponer de tiempo de vida. No es extraño, así, que utilicen la metáfora de la "mili", una especie de institución total en la que espacio y tiempo parecen estar férreamente controlados por otros, para referirse a su modo de vida.

\section{LAS ESTRATEGIAS PERSONALES DE BÚSQUEDA DE TIEMPO LIBRE DURANTE LOS FINES DE SEMANA}

Cuando el modo de vida está íntegramente constituido por el tiempo de trabajo, cuando los únicos períodos de tiempo libre de que dispone el trabajador están invertidos, esto es, coinciden con los períodos de trabajo del resto de las personas, la búsqueda del tiempo libre se erige en el principio rector de la gestión personal del tiempo de vida.

El trabajador de fin de semana no permanece impasible ante las constricciones objetivas que le impone su estructura de tiempo laboral, sino que reacciona estableciendo diversas estrategias personales de búsqueda de tiempo. Un martes, como hemos visto, no es lo mismo que un sábado o un domingo. La invalidez social del tiempo invertido hace que el trabajador deba seguir buscando tiempo, pero tiempo con suficiente valor tanto social como personal, tiempo de vida, tiempo libre, tiempo de ocio en lo que constituye "su" habitual período de trabajo, esto es, durante los fines de semana. Ante la invalidez del tiempo de los días 
RIS

REVISTA INTERNACIONAL DE SOCIOLOCIA

№ 38, MAYO-ACOSTO, 2004

EDUARDO BERICAT

laborales, la búsqueda del tiempo de ocio queda marcada indeleblemente por la falta de tiempo. El tiempo de ocio se convierte así en un recurso muy escaso para el trabajador de fin de semana. Pero no sólo por la falta de tiempo, sino también por la falta de energía. Dado que el trabajador tiene que embutir en un mismo período de tiempo el "trabajo" y el "ocio", la búsqueda del tiempo libre se establece como una lucha contra la fatiga y contra el sueño. Para disponer, al menos, de algo de tiempo libre durante el fin de semana, el trabajador se ve obligado a robar el tiempo. Pero como resulta bastante improbable que pueda robar tiempo al tiempo de trabajo, dado su escaso poder y estatus laboral, la única salida que le queda es robar tiempo de descanso o sueño echando un forzado pulso a su propia resistencia física, esto es, robar-se descanso, robarse sueño.

$\mathrm{Al}$ trabajador aún le queda una tercera estrategia o posibilidad, que consiste en postergar el tiempo libre. Pero ésta es un mera estrategia de adaptación. Consiste en eludir la completa renuncia al disfrute normal del tiempo libre atrasando o aplazando el tiempo de ocio a un futuro, más o menos próximo o lejano, con fecha más o menos fija o indefinida. Un futuro imaginado en ensueños cargados de ilusión que expresan la íntima voluntad de resistencia que siempre emana de la libertad. Ensueños de futuro tiempo libre que, como todos los sueños humanos, expresan tanto la necesidad de adaptarse al principio de la realidad, como la imposibilidad de renunciar a lo que es en sí mismo valioso y deseable. Por último, cuando los sueños se apagan, dejando tan sólo la pura y llana adaptación, puede percibirse tras este sometimiento y esta definitiva renuncia el triste sabor de la derrota, la triste, humillante y rumorosa resignación del sujeto que ha de seguir viviendo agachando la cabeza. Del sujeto enfrentado a la imposibilidad de huir y enfrentado a la imposibilidad de luchar. Si la búsqueda del tiempo termina en flagrante fracaso, asoma con fuerza en los trabajadores de fin de semana una clara y consciente sensación de que se están "perdiendo cosas", de que las buenas cosas de la vida discurren ante su vista sin que ellos puedan hacer nada por atraparlas.

[18] - La hostelería es muy duro porque le tiene que gustar a uno mucho para estar en ello.

- No tienes vida, con la hostelería no tienes vida sobre todo ...

- Es muy ingrata.

- ... es ingrata, sobre todo en las zonas como aquí en la costa.

- Las horas de trabajo ... (16:147)

[19] - Los sábados y los domingos, ¿yo salir un sábado por la tarde?, si yo salgo..., termino de trabajar, que es mejor horario que el tuyo, a lo mejor, ¿no?, pero termino a las doce, llego a mi casa a la una, hecho polvo, después de estar aguantando..., porque el sábado además para mí es el peor día, está buscando todo el mundo los problemas, la gente que llega... , bueno, todo lo que pasa, ¿no? Llegas a tu casa a la 
una de la noche, te duchas, son las dos, ¿dónde vas?, buscar ..., ¿cómo vas a buscar a los amigos?

- Puedes intentarlo... (16: 105)

[20] - Cuando nosotros más rumbosos estamos es cuando está la gente más decaída, que es en invierno, es cuando estamos nosotros más rumbosos, y en verano, cuando está la gente más rumbosa es cuando estamos nosotros más tumbados, ¿no? Y la cosa es sobre todo el darte cuenta, porque a mí, el problema que yo tenía es que durante mucho tiempo no te das..., no me daba cuenta, es decir, yo no era consciente de que estaba desperdiciando el tiempo, el tiempo, el tiempo, porque el tiempo si lo buscas lo encuentras, porque encontrarlo lo encuentras, te lo quitas de sueño, te lo quitas de donde sea, pero tienes que quitártelo del sueño, porque como no te lo quites mal asunto, ¿sabes?, yo por lo menos me he dado cuenta de que yo por lo menos cuatro o cinco años los he perdido estúpidamente, y ya no estoy dispuesto, y ahora lo busco, es decir, ahora es activo, es decir, yo tengo que buscar tiempo porque tengo que hacer cosas y tengo que sacar ocio para mi, para mi mujer, para los amigos, para todo, ¿no?, y normalmente la gente no lo busca porque claro, trabajan de lunes a viernes, el viernes por la tarde está libre, todo el mundo sale, ellos salen con el resto de la gente, porque hacen lo mismo que el resto de la gente, el domingo pues hacen lo que hace la mayoría de la gente, van a la playa, van a esto, van a lo otro, entonces a ellos el ocio les llega directo, y nosotros tenemos que ser conscientes de que tenemos que buscarlo y buscarlo, y si no lo buscas lo pierdes, y yo por lo menos durante los cuatro o cinco años que he tardado en darme cuenta de eso lo he perdido, y ahora espero no perderlo, espero.

- ... es que nosotros somos una minoria que damos placer a una mayoría ... (16: 121)

Sería difícil encontrar otro párrafo que transmitiese con tanta exactitud y viveza, y de modo tan completo, la tensión dramática a la que se ven sometidos los trabajadores de fin de semana en la búsqueda del tiempo. Todos y cada uno de los elementos teóricos esbozados al principio de este epígrafe, al describir el modelo personal de gestión del tiempo, se encuentran aquí plasmados en una perfecta síntesis vital. Este extracto, por añadidura, introduce un importante elemento de reflexión, cual es el de la conciencia de las situaciones objetivas a las que estamos, de múltiples maneras, sometidos los seres humanos. Durante mucho tiempo el trabajador no se había dado cuenta de que había estado desperdiciando el tiempo. Y, sin embargo, al parecer, esta falta de percepción no sólo no impidió la pérdida del tiempo, sino que todavía la agravó más, si cabe. El clásico postulado de Thomas sostiene que si una situación es definida por un actor como real, aunque no lo sea, será real en sus consecuencias, lo que ha dado lugar, como es bien sabido, a diversas orientaciones explicativas de la conducta que ponderan en exceso, o en exclusiva, el efecto de los componentes simbólicos. Ese postulado, 
sin embargo, ha de complementarse con otro que podría formularse como sigue: aunque las situaciones no se definan como reales, si lo son, serán reales en sus consecuencias. La situación de escasez de tiempo, de la que el actor puede o no ser consciente, constituye una situación objetiva de su modo de existencia. Esta situación, al menos mientras dure, determinará inexorablemente su efecto, esto es, la pérdida del tiempo. Incluso cuando el actor, de repente, descubre la realidad y se hace propósitos de buscar el tiempo y ganarle así la batalla, la situación real seguirá condicionando su modo de vida. De ahí ese suspensivo y escéptico final con el que el trabajador de fin de semana concluye su párrafo. Y ahora espero no perderlo, espero....

Con o sin conciencia explícita de la situación real, la escasez y la búsqueda de tiempo libre parecen ser constantes que afectan, si bien en diverso grado, a todos $\mathrm{y}$ a cada uno de los trabajadores de fin de semana. Todos ellos son buscadorres de pequeños huecos de tiempo, aprovechadores de los huecos del tiempo.

[21] - y siempre buscamos el cafecito, la cervecita por la noche..., siempre se busca; aunque no les vea a ellos, que están trabajando también en McDonalds los fines de semana, pero yo sé que el miércoles por la noche nos vamos a tomar una copita, y el jueves pues nos vamos a tomar un café, y siempre hay... Siempre hay... (15: 107)

[22] - el poco tiempo que tenemos pues lo aprovechamos y vamos tirando como podemos. Los fines de semana, hombre, yo estudio, estoy estudiando, en invierno estamos un poquito más sueltos, y nos podemos ver un poco más y tal, pero llega el verano y para mí, yo la ideología que tengo es esa, el verano es para trabajar y el invierno es para estudiar. Y el verano vamos a muerte. El tiempo que la veo lo aprovecho para ... en verano nos vemos menos, nos contamos menos cosas, pero el poco tiempo ... (15:30)

[23] - Yo llevo seis años con mi novia y hemos pasado todos los baches esos de trabajar un fin de semana.

- Pero son baches como tú dices.

- Sí, pero lo hemos superado bien, o sea, lo hemos superado creo yo que, un poco de comprensión por ella, pero también me ha costado mi trabajo, porque yo tenía que buscar hueco donde no lo habia. Buscaba el huequecito, ella estaba estudiando Química y yo estaba allí en Derecho, pues yo me iba y me tomaba un cafelito con ella, buscaba sitio. Que cuando no tienes nada que hacer no lo buscas, quedamos a las nueve. Si tenía una hora que no tenía clase pues me iba con ella porque sabia que el fin de semana no nos ibamos a ver. (15:38)

[24] - También pues la novia y eso te quita más tiempo, no te quita más tiempo, disfrutas con ella, ya no disfrutas tanto con tus amigos, tienes que repartir el poco tiempo que tienes entre dos personas, entonces ya..., entre dos, tres o lo que sea, ¿no?, entonces ya menos tiempo todavia, tenemos que trabajar...(15:104) 
La búsqueda del huequecillo de tiempo constituye la estrategia realista de los trabajadores del fin de semana pero, como ya comentamos anteriormente, existen tres estrategias imposibles: la estrategia orientada al conflicto laboral del trabajador con la empresa; la estrategia de la heroicidad o de las hazañas de tiempo; y, por último, la estrategia de los ensueños de ocio.

\section{Conflicto laboral:}

[25] Me pusieron, bueno, se quedó la cosa en una discusión, la semana siguiente tuve que abrir todas las mañanas, y el fin de semana cerrar todas las noches y me echaron, claro me echaron porque es que yo no aguantaba más. Y yo dije ... bueno, ¿ $Y$ los fines de semana ni librar ni hostias?, ni libraba. Allí se libra dos días seguidos, lunes-martes, a la semana siguiente martes-miércoles. Yo cuando llegaba el jueves me pasaban otra vez al lunes, lunes-martes, martes-miércoles. Entonces pues yo decía, no llego al viernes ni al sábado. (15-50)

H- Los horarios los emplean como forma de ... si te gusta más o menos.... le metes ...(15:55)

[26] - A los seis meses cogí un, vaya, cogí un estresismo que era grandioso, después de Semana Santa, pero estresado totalmente. Le dije que me iba. Al final, ¿qué he conseguido? Que me ha hecho fijo.

- ¡Qué suerte!, eso es suerte.

- Me ha hecho fijo, me dio tres días para que me quitara el estrés porque se lo dije. Me fui a Cazorla, cuando vine de Cazorla .... Me ha puesto peor, el peor turno que hay. $(16: 168)$

[27] - ¡Jolín!, pero es que el trabajo es lo que dice él, el trabajo es el trabajo y más cuando tienes una situación precaria que no puedes tampoco abusar. Porque basta que te coincida que dos días has hecho una cosa y que luego la tercera vez tengas que pedir otra vez permiso porque..., pues ya te sientes mal, porque ya sabes que al final van a prescindir de $t i$, y como nadie es imprescindible... pues esa es la impotencia que tú tienes, ese miedo, miedo e impotencia.(15-72)

[28] Lo que hicieron cuando se iba a cumplir mi contrato, poner un anuncio, hicieron 20 entrevistas, delante mía, pero a 20 metros, para que yo lo escuchara lo que decía, ¿no?, y cuando terminó la 20 entrevista me llega y me dice: "mira oye, que resulta que hay un puesto de trabajo, tú termina el contrato, el puesto de trabajo es esto, las condiciones son estas, que lo quieres coger, lo coges, si no ya sabes que hay 20 esperando". Que también, no te creas tú.... (16: 87)

[29] - Yo he llegado un momento que tuve que coger mi empresa, ponerme muy serio, poner las cosas, es decir mira, me voy y me voy, porque está o mi pareja o mi trabajo. 
RIS

Me he puesto a pensarlo y yo para mí no hay mucho que pensar, es decir, me voy, ya está, es que me voy. Entonces ya han buscado un apaño intermedio que más o menos ahora mismo es aceptable. (16-140)

\section{Hazañas:}

[30] - me calentó un amigo: "vámonos de juerga, vámonos de juerga", en principio vámonos a la feria de Córdoba, sábado de feria, así de gente, ni un puñetero sitio donde quedarnos a dormir, y estando en Córdoba dijimos: “¿nos vamos a ir a Marbella?”..., y Eduardo cogió y se plantó en Madrid con el coche, sin dormir, salió de cena, salió de juerga, durmió dos horas, cogió el coche y se vino a Marbella a trabajar.

- Eso es muy fuerte, eso es muy fuerte. Eso se hace lo que es una vez.

- Una vez.

- (Risas de todo el grupo) (16-79)

[31] - Tú imagínate que yo llego un día, me he pegado un juergón, no he dormido prácticamente nada, estoy hecho polvo, me he tomado un guaraná, un par de cafés y tal, me espabilo un poquito y en mitad de la mañana ya por mucho café que te tomes ya la mente no te funciona, se te olvidan las reservas, ¿sabes?

- Y además se te cae el pelo luego.

- A ti se te cae el pelo, pero también a los otros (los clientes), no veas. Si tienes mucha responsabilidad tampoco puedes arriesgarte a eso. Porque eso lo haces un dia. (16-129)

[32] - desde que empezamos a trabajar pues nos vemos poco, o nos vemos los fines de semana pero ya reventados de toda la semana, por las noches y eso vemos un ratillo..., mira, que yo estoy muy cansado, me voy..., que eso, y cuando te quedas ya después el domingo lo resientes mucho más, ya el próximo domingo dices: "mira, vamos a dejarlo, si nos vemos vamos a vernos un miércoles, que estamos más descansados y eso", pero ya rompe un poco más los esquemas de lo que tú quieres hacer, (15103)

[33] - Te lo tienes que buscar. Sí, lo tienes, pero te lo tienes que buscar y quitar del sueño.(16:19)

\section{Ensueños:}

[34] - Y decía yo, pues jueves, viernes, sábado, preguntaba a mi jefe, cuando estaba en el restaurante, mira, ¿te importaría si no viniera ese sábado? Es que me gustaría irme con mi novia. Nos poníamos el jueves, dentro de dos meses, decía a mi novia, el día tal nos vamos a ir los dos, nos vamos a perder por ahí arriba, nos vamos a ir a Nerja, nos vamos a ir a Canillas, nos vamos a ir a una casa rural. Y si había malos 
rollos de estos de ... "Ya te podías venir conmigo al centro, que hay que ver, que me voy con todas las parejitas y tú te quedas, tú trabajando y yo con todas las parejitas, alli de farolita". (Yo le decía) tú no te preocupes que tú verás el fin de semana que nos vamos a pegar o tú verás el día ... tú no te preocupes, tú ... pues el día tal nos vamos a ir para allá. Y ya está. Y nos poníamos así, nos poníamos unas metas. Lo malo era cuando se acababa ese fin de semana. (15:82)

[35] - ¿Os ha ocurrido, habéis pensado del trabajo que tenemos de hostelería los fines de semana que tú has dicho eso de quitarte de en medio y meterte en Canillas de... o más lejos todavía y que nadie te moleste?

- Eso es lo mejor que hay. Es que cuando te sale ... eso es desconectarte total. Sin móvil, sin nada, sin televisión en la casa, sin radio...

- El único inconveniente que te manipulan el ... el turno te lo manipulan sin previo aviso, cuando les place, ¿no? A lo mejor tú tienes hechos planes para yo qué sé, y tú descansas..., yo descanso los lunes, y a menudo hago planes, para quitarme de Marbella, para quitarme de España, para...

- (Risas de todo el grupo) (16-68)

[36] - Planeé hace poco, planeé un viaje hacia Granada, a una especie de casas así en el ... . Total que cogí y me dicen: "el lunes no puedes descansar porque...", eso me lo dijeron 6 horas antes de terminar de trabajar al domingo, "mañana no puedes descansar porque es que nos haces falta"; Mañana es lunes, ¿usted no me ha podido avisar con un poquito de antelación?, tengo hechos mis planes, he dado un dinero a cuenta para ..., y dice: "pero es que no puedes porque no puedes", y si no puedo, no puedo dejarlo ... Sin ningún reparo. (16:68)

[37] - me dijeron: "no te preocupes que hasta julio tú no tienes problemas", yo me enteré de que había un concierto hace poco, compro mi entrada, y justo me dicen: "oye, que trabajas los fines de semana", tenía tres entradas a 2.500 cada una. (yo) diciendo... : "mi hermana irá, mi hermano irá y yo me quedaré aquí"

- (Risas de todo el grupo)

- ¿Qué hago ahora con el dinero?

- A veces no es el dinero, a veces es la ilusión que pones.(16: 71)

[38] - Los Rolling, madre mía los Rolling, no sé cuántos, venga, la entrada de los Rolling, llevas seis meses; qué bien, y falta un mes para ver a los Rolling, faltan dos semanas para ver a los Rolling, y el sábado que viene tienes que trabajar por narices, ¿pero cómo?, por narices. No, el ticket no es problema, vamos, la entrada no hay problema para venderla, pero la decepción es horrible, ¿eh? (16: 73)

La estrategia del conflicto laboral, es decir, de la demanda de tiempo de ocio a la empresa, es tanto más imposible cuanto menor sea el poder laboral y el poder 
de mercado de los trabajadores. Pedir permisos eleva la probabilidad de que prescindan de ti en un mercado en el que nadie es imprescindible. Las demandas de tiempo libre, o los incumplimientos de horario de trabajo, te enfrentan directamente a la realidad del despido. Las condiciones de trabajo son éstas, los horarios son éstos, o lo tomas o lo dejas. En la puerta hay veinte como tú esperando. En un mercado de trabajo altamente desregulado, la amenaza de despido funciona como óptimo mecanismo de control de aquellos trabajadores que se atreven a rebelarse contra el tiempo de la empresa. En una versión aparentemente más dulce, que en principio no pretende excluir al trabajador, pero que finalmente lo consigue, nos encontramos con el manejo disciplinario del tiempo de trabajo. Te ponen el peor turno que hay, aunque a veces, si el trabajador no es del todo prescindible, se puede llegar a apaños intermedios que le permitan encajar a éste su tiempo de trabajo y su tiempo de vida. En general, sin embargo, surgen sentimientos de miedo y de impotencia.

La estrategia heroica de la búsqueda del tiempo, las hazañas personales contra el tiempo, resultan también imposibles. Son fugaces e ilusorias victorias contra el tiempo que sólo pueden realizarse, a lo mucho, tan sólo una vez, y no sin evidentes costes y riesgos para el propio trabajador. Se te puede caer el pelo, y además tienes que luchar contra el cansancio y el sueño. En realidad, robas tiempo del tiempo de descanso o del tiempo de sueño, y eso sólo puede hacerse a costa de una gran fatiga, a base de estimulantes y si eres joven. Aun así durante no demasiado tiempo. Si quiere permanecer en la hostelería, el trabajador tendrá que adaptar su vida, aunque eso "rompa un poco más los esquemas de lo que tú quieres hacer".

Figurar una utopía y una ucronía, un lugar que es un no lugar, y un tiempo que deja de ser tiempo medido y cronometrado, parece una elucubración bastante común entre los trabajadores de fin de semana. Tanto más común cuanto más estén sometidos a la férrea disciplina del tiempo, cuanto más difícil les resulte encajar los tiempos de trabajo en los tiempos normales de vida. El extracto 34 es paradigmático a este respecto. Con qué cariño ingenia el trabajador un mecanismo para borrar, o al menos atemperar, las actuales y bien reales insatisfacciones de su novia. Se sustraen al peso del presente imaginando proyectos de futuro: .... nos vamos a ir los dos, nos vamos a perder por ahí arriba, tú veras el fin de semana que nos vamos a pegar, ya verás el día ..., tú no te preocupes. Todos sueñan con quitarse de en medio, con desaparecer de España, del mundo, con desconectarse totalmente del trabajo. Y para eso hacen planes lúdicos cargados de ilusión. Un viaje, un espectáculo, un partido de fútbol o un concierto de los Rolling Stones. $\mathrm{Y}$ aquí de nuevo aparece la imposibilidad, las horribles decepciones causadas por la arbitrariedad y la imprevisibilidad del tiempo de trabajo que es capaz de segar, incluso, estos utópicos y muy queridos ensueños de los trabajadores de fin de semana. Y como en muchas otras circunstancias de la vida, lo importante no es el dinero que pierdes, lo importante es la ilusión que pones, que pones y que 
pierdes. Por esto la imprevisibilidad del tiempo de trabajo afecta a lo más hondo del ser, a sus sueños, y por este motivo "quema", y también por esto se recuerdan por largo tiempo tanto las grandes como las pequeñas y cotidianas decepciones.

Así que, finalmente, el trabajador del fin de semana, fracaso tras fracaso, ha de conformarse con ver pasar la vida sabiendo que se está perdiendo cosas, sabiendo que perderá el hilo de muchas relaciones sociales, sabiendo que perderá sus aficiones, sabiendo que le será difícil compartir con otras personas sus tiempos de ocio, que sólo el ocio solitario le será accesible. Además no creen que el problema del tiempo de trabajo en la hostelería tenga solución. Como dice uno de los participantes del grupo, "hazte a la idea de que tú comes de los fines de semana, de que tú tienes tanto dinero por los fines de semana. Que te interesa, bien, que no, lo dejas. Vamos, si te interesa tienes que conformarte e intentar adaptar tu vida a ese horario de trabajo, a los fines de semana, por muy sacrificado que sea tienes que ... Solución esa. O te vas o te conformas con lo que tienes" (15: 59). Así pues, y pese a las condiciones de trabajo perfiladas hasta ahora, vemos que los trabajadores han naturalizado su situación con una idea de necesidad insoslayable: para que haya una persona tomando una copa en un bar tiene que haber otra, al otro lado de la barra, que se la ponga. Pero esta naturalización de la realidad, como ya se dijo antes al comentar el postulado de Thomas, tampoco impide que tal situación produzca efectos reales.

\section{LAS RELACIONES FAMILIARES Y DE AMISTAD DEL TRABAJADOR DE FIN DE SEMANA}

Elizabeth Bott, autora de un magnifica investigación publicada bajo el título Familia y red social, puede ayudarnos a ubicar teóricamente las consecuencias que comporta el trabajo de fin de semana para las relaciones sociales y, en concreto, para las relaciones conyugales, esto es, para las relaciones entre marido y mujer. El concepto clave a considerar es el de rol relacional de la pareja. Desde esta perspectiva, la autora encontró dos tipos opuestos de familia. En unas familias "el marido y la mujer compartían tantas actividades y pasaban juntos tanto tiempo como podían", mientras que en otras, al contrario, "el marido y la mujer realizaban todas las tareas posibles de forma separada e independiente" (Bott, 1990: 91). En atención a este hecho puede hablarse de un gradiente con dos polos extremos de familia: aquéllas en las que predomina un rol relacional conyugal conjunto, y aquéllas en las que predomina un rol relacional conyugal separado. Ambos tipos de familia, dependiendo de la cultura, podían ser aceptados y considerados "normales" por sus propios miembros.

Elizabeth Bott trató de investigar las causas del diverso grado de segregación conyugal, y descubrió que este fenómeno estaba íntimamente relacionado con las relaciones sociales externas mantenidas por el marido, por la mujer y por la 
R I S

REVISTA INTERNACIONAL DE SOCIOLOGIA

№ 38, MAYO-AGOSTO, 2004

EDUARDO BERICAT

familia en su conjunto. Visto que estas relaciones adoptaban la forma de una red social, y vistas las diferencias de conectividad existentes en las diversas redes sociales externas, pudo sugerirse "que el grado de separación de roles conyugales está relacionado con el grado de conectividad en la red total de la familia. Aquellas familias que mostraban un alto grado de separación entre los roles relacionales del marido y la mujer tenían una red trabada, muy unida: muchos de sus amigos, vecinos y parientes se conocían entre sí. Por el contrario, las familias cuyos roles relacionales se presentaban relativamente conjuntos entre el marido y la mujer tenían una red suelta, poco unida: pocos de sus parientes, vecinos y amigos se conocían entre sí" (Bott, 1990: 99). La explicación última de esta curiosa relación, según Bott, se basa en el hecho de que "si las redes sociales externas de un matrimonio son poco densas y están poco unidas, entonces el marido y la mujer se ven obligados a buscar uno en el otro algunas de las satisfacciones emocionales y de ayuda en las tareas familiares que las parejas con redes muy unidas pueden obtener de personas externas a la familia" (Bott, 1990: 100).

En relación con el trabajo de fin de semana, y según lo expuesto, cabe esperar que las consecuencias de la inversión del tiempo de trabajo y ocio del marido con respecto a la mujer, serán mayores en aquellas familias en las que predominen los roles relacionales conyugales conjuntos. En estas familias, el mantenimiento de relaciones mutuas, de relaciones afectivas y de relaciones sexuales gratificantes determinaban el contenido moral de un "buen matrimonio". En ellas no está bien visto que uno de los miembros salga sin el otro, prefiriéndose ante todo la diversión conjunta. Los amigos deben ser amigos de los dos miembros de la pareja. En caso contrario, surgirán problemas que irán minando esa amistad. La relación mutua, esto es, la fidelidad e implicación con el propio cónyuge debe ser siempre superior a la que se dispense a cualquier otro familiar, por ejemplo al padre o a la madre de cada uno. Por último, Bott encontró que la mayoría de las mujeres de este tipo de familias, aunque en diverso grado, "se quejaban de soledad, de aburrimiento y de cansancio" (Bott, 1990: 123).

Tras esta breve descripción, y conociendo el contenido de los extractos transcritos hasta ahora, podrán fácilmente imaginarse las consecuencias que sobre las relaciones de pareja pueda tener el hecho de que uno de los cónyuges trabaje el fin de semana. No es sólo que los modelos normativos de familia estén evolucionando desde la familia linaje hacia la familia sentimental (Ariès, 1987). Es, ante todo, siguiendo a Bott, que las redes sociales externas de la familias en la contemporaneidad posmoderna son cada vez más redes, redes en las que desciende progresivamente su densidad social y desciende progresivamente su conectividad. Así pues, el matrimonio contemporáneo ofrece, casi en exclusiva, como bien único y fundamental de la institución, la convivencia compartida entre dos personas aisladas que han de ofrecerse y esperan recibir mutuo afecto $\mathrm{y}$ ayuda. $\mathrm{Y}$ es este último reducto de la sociabilidad comunitaria posmoderna el que pone precisamente en riesgo el trabajo de fin semana. El trabajo de fin de 
semana mina la base existencial del rol conyugal conjunto que caracteriza a la sociedad posmoderna ${ }^{6}$.

A continuación veremos cómo el discurso de los trabajadores de fin de semana se ajusta, en líneas generales, si bien con importantes matizaciones, a estos planteamientos teóricos. El tiempo normativo para la convivencia entre cónyuges es en la actualidad el tiempo de ocio, lo que en el ciclo semanal equivale al fin de semana. Un descenso del tiempo de convivencia durante el fin semana, por tanto, estará asociado negativamente con el sentimiento de unidad conyugal, al que podríamos denominar, en claro contraste con el amor-pasión (Trías, 1997), como amor-matrimonio ${ }^{7}$. Los trabajadores de fin de semana lo saben por propia experiencia, de ahí que muestren su preocupación. Antes ya se transcribió el tajante comentario de uno de los miembros de un grupo, "la mujer, el problema es la mujer", aludiendo al hecho de que en el trabajo de hostelería lo peor no son las condiciones de trabajo que han de soportarse, sino las consecuencias que tienen sobre relaciones sociales y, en particular, sobre la relación conyugal.

El contexto básico viene definido por el hecho de que tanto el marido como la mujer han de prescindir de lo único valioso que hoy aporta el matrimonio, es decir, el otro, la persona del otro, el tiempo del otro, la actividad conjunta con el otro. Siendo esto así, el vínculo conyugal puede debilitarse e incluso deteriorarse conforme avanza el tiempo de relación. Una prolongada convivencia conyugal con una escasa coexistencia espacio-temporal no tiene sentido para el vigente modelo de matrimonio, basado en los vínculos afectivos y en la realización de actividades conjuntas. Incluso la amistad termina perdiéndose o deteriorándose. Pero, como dice un miembro del grupo, remarcando adecuadamente el absurdo, si los cónyuges no se ven, porque no coinciden sus horarios, "imagínate qué convivencia".

\footnotetext{
${ }^{6}$ Como es obvio, sus efectos serán menos perniciosos cuanto más esté constituida la familia sobre la base de roles conyugales separados. Esto se observa, por ejemplo, en un grupo de discusión realizado con mujeres de trabajadores de la hostelería que trabajan en la Costa del Sol, pero que viven en un pequeño pueblo cercano. Las redes sociales que mantienen estas mujeres en la localidad con vecinas y familiares mitigan los efectos de la falta del marido y, correlativamente, reducen tanto la cantidad como la intensidad de las demandas y quejas hacia el marido.

${ }^{7}$ Hemos testado la hipótesis de la relación entre "tiempo de convivencia en pareja" durante el fin de semana y "amor-matrimonio". Utilizando la matriz de datos originales de la encuesta correspondiente al Estudio 2.157 del Centro de Investigaciones Sociológicas, sobre Actitudes y conductas interpersonales de los españoles en el plano afectivo, construimos mediante un Análisis de Correspondencias Múltiples la variable "amor-matrimonio", y posteriormente estudiamos las correlaciones de esta variable con el "número de horas en días laborales de la semana" y con el "número de horas durante el fin de semana" pasadas con la mujer. Los resultados indican que una disminución del número de horas en días laborales no está correlacionada con un descenso en el valor de la variable "amor-matrimonio", mientras que un descenso del número de horas de convivencia en el fin de semana, por el contrario, sí que lo está. Esta última correlación es estadísticamente significativa.
} 


\section{Convivencia}

[39] - Mientras estoy trabajando me gusta lo que estoy haciendo, pero lo que no me gusta es a lo mejor las consecuencias que traen para otras personas y para ti mismo, claro. (16: 180)

[40] - Estoy de acuerdo con él porque yo también tenía una pareja y aparte tenía amigos, pero es que a raíz de estar todo el año, la verdad que perdí las amistades. La pareja, vamos ... mi pareja seguía sola, sobre todo porque el domingo es el día que más o menos se puede "quedar", y no podía porque siempre tenía que trabajar. Aparte, si no trabajaba el domingo estaba hecho polvo porque el banquete era el sábado por la noche y salía de trabajar a las siete de la mañana. En fin, un rollo para quedar y para todo, el domingo ...(15:24)

[41] - La amistad no se llega a perder, pero cuando se trata de una pareja, que compartes muchas más cosas, necesita que la atiendas.

- Hombre, alimentarla se llama eso.

- Alimentar la pareja. Entonces en el momento en que no la alimentas es como una planta, se seca. Hay que regarla.(15: 112)

[42] - Eso es lo único bueno que tengo yo, cuando ella descansa le dan vacaciones y le dan en invierno y a mi también.

- Menos mal.

- Es el único ratillo que nos podemos ver los ojos.

- Menos mal. (15: 44)

[43] Pero si no se ven, porque no coinciden con los horarios, jimagínate qué convivencia!. (15: 88$)$

El problema del trabajador del fin de semana no estriba, tan sólo, en el poco tiempo de coexistencia del que dispone en su convivencia conyugal. Estriba, por añadidura, en el contenido de ese ya de por sí escaso tiempo, que tiende a ser capturado por las demandas de la familia y de la mujer del trabajador. El supuesto "tiempo de ocio" se transforma finalmente en un tiempo indeseable, que es rechazado por el trabajador. El rechazo de este tiempo, demandado principalmente por la mujer, acaba siendo interpretado por ésta como un repudio procedente del marido. Nos encontramos así con la primera asimetría conyugal del tiempo. La mujer tiene una idea para llenar el tiempo disponible del marido, pero el marido parece tener otra bastante diferente. La escasa coexistencia, por este motivo, se convierte en tormento para ambos cónyuges $y$, por supuesto, en motivo de conflicto. El trabajador preferiría dedicar su escaso tiempo a descansar, a ver la tele o a salir con sus amigos. Pero las obligaciones familiares 
le reclaman. Así que el supuesto tiempo de ocio acaba siendo mero tiempo de "disfrute" entre comillas, un tiempo de obligaciones planificadas, como el tiempo de trabajo, y un tiempo en el que hay que disimular el disgusto, por lo que, al igual que en tiempo de trabajo, el trabajador debe poner "buena cara", en este caso a su mujer. La mujer espera y demanda ese tiempo, mientras que el marido llega a temer y a rechazar ese mismo tiempo. El escaso espacio para la coexistencia de los cónyuges configura, así, el escenario de un primer y radical desencuentro.

\section{Desencuentro}

[44] Yo tenía novia, también, ¿no?, llegaba a mi casa a lo mejor pero yo no quería ir con mi novia, yo quería acostarme o yo quería pues venga estar un ratito viendo la tele o irme con mis amigos y tomarme una cerveza. Sabes, que no quería, tenía mis problemas y no quería a lo mejor, no es que tuviera problemas con ella, pero sabes lo que pasa con el tema de las parejas que siempre te cuentan una historia en el momento menos adecuado ... (15-32)

[45] Ella acusaba eso que un día que tenía libre pues no se lo dedicaba a ella y que cuando salía de trabajar, no es que no quería estar con ella, sino que prefería hacer otras cosas más que estar con ella. Ella acusaba eso.

$\mathrm{H}-$ En mi caso no. Yo el tiempo que tenía libre pues lo dedicaba con ella. (15.169)

[46] - Tú tienes una hija que la tienes que sacar, que ella quiere ir al cine, que el día que estás cansado y que puedes estar tranquilo, mucha veces les tienes que decir: "hoy nos vamos al cine..."

- Encima de ..., estás cumpliendo con otra...(obligación), en casa, tienes que cumplir en casa.

- Que ese disfrute lo sientes como una obligación, y tu mujer lo nota, tu familia lo nota. Sí, se cumple una monotonía... (15:1)

[47] - Pero bueno, sí, de vez en cuando también es muy difícil compaginarlo con tu pareja, ¿no?, porque aparte de que tienes poco tiempo de ocio, porque hay veces que a lo mejor no te apetece estar con ella, y si estás con ella a lo mejor no tienes ganas de nada, pero tienes que poner buena cara, y ya te vuelve otra vez a recordar el trabajo, porque tú detrás de una barra tienes que estar con buena cara, tienes que parecerle simpático siempre al cliente, y dices: ¡vaya por Dios! (16:103)

- Entonces esos tiempos, porque claro, me lleva a comprar, me lleva a no sé qué, tengo que poner buenas caras...

- Eso los casados. Eso sobre todo, la buena cara, que te recuerda a tu trabajo. (16: 116) 
[48] "Estamos hablando de tiempos donde uno disfruta, tiempos de disfrute con tu pareja..." (Intervención del moderador)

- Entre comillas.

- Es que te tienes que hacer a que ese es tu disfrute, en el fondo... (16:116)

- Ese es otro problema, que llega el dia descanso que ya sabes que...

- Tienes el orden del día planificado. (16:96)

La segunda gran asimetría del tiempo conyugal de los trabajadores de fin de semana se deriva de la responsabilidad personal que puede atribuirse a cada uno de los miembros de la pareja. En este caso, los maridos llevan la peor parte. Ellos son los responsables directos de la situación tan desfavorable que afecta a la pareja, ya que "su" trabajo es el factor causal determinante. Al parecer, estos trabajadores no tienen muchas otras opciones laborales, ya que la inversión de tiempo que causa el conflicto entre marido y mujer es reflejo de su posición social o, más específicamente, de los recursos de mercado con los que cuentan estos trabajadores. Están atrapados en una posición estructural que les aboca a un dilema vital: o tiempo o dinero. Las mujeres imputan responsabilidad, y de este modo responden agriamente al repudio. Bien sueñan con la posibilidad de que su marido pueda dejar el trabajo ("ojalá tuviéramos otra cosa...."). Bien presionan directamente para que los maridos abandonen la profesión. Pero los maridos se muestran mucho más escépticos. Y algunos, con ironía, les responden: "bueno, búscame un trabajo".

\section{Responsabilidad}

[49] - Sí, porque está sola.

- ... y entonces tú dices: "es que yo no puedo porque si yo dejo esto, ¿de qué vamos a comer y tal?". ¿Comprendes? Y ya viene la ...(pelea)

- Llega un día que cae la gota que colmó el vaso y dices, pero, ¿qué es lo que ha pasado? El único conflicto es que he llegado una hora tarde, ¿a qué viene eso? (16: 155)

[50] - Vete con ellos. “¿Y yo qué hago sola con los amigos y tú aqui?" Tú te vas a quedar aquí en la casa, ¿y por qué tienes tanto interés? No, ya hay dudas. "¿A ti no te importa que yo me vaya con los amigos?" Porque claro, son los amigos, pero tú te quedas solo. Y si no se va, pues claro, (me dice) "ellos se han ido a Cazorla pero yo me he quedado aquí ... me he quedado aqui porque tú tienes ese trabajo y porque tienes ese horario". Yo mientras trabajo. Muy bien ... (16: 181)

[51] - Las novias a veces son peores, porque como las ves nada más que los fines de semana o de vez en cuando, porque a ti te pasará, yo he tenido novia..., todo el que hemos tenido novia alguna vez que otra, y que te diga: "bueno, y por qué no dejas el 
trabajo, porque te están explotando, porque no sé qué, no sé cuántos...”, y empiezan a agobiarte y tú dices: "bueno, búscame un trabajo..."

- (Risas de todo el grupo) (16: 41)

- Hombre, eso es lo normal, eso es lo normal en una pareja de que ella te diga, ojalá tuviéramos otra cosa ... (15: 78)

[52] - (a la empresa)... ni os estoy amenazando ni nada, es que me voy ... Luego cuando no tengas, yo qué sé, a lo mejor me falte dinero para comer, me falte para esto, me falte para lo otro, pues puede que igual mi mujer lo comprenda o no lo comprenda, o diga, pues mira, pues vale ... pero vamos a tener una relación, vamos a salir, vamos a tener una vida social. Vida social que ya es nula. (16:143)

Los trabajadores de fin de semana "saben" de su responsabilidad, pero "callan". El dolor de la vergüenza se oculta tras un término, obsesivamente repetido en los grupos, cuyo significado nunca se hizo explícito: comprensión. Los trabajadores imploran la comprensión de sus mujeres. Y es que sólo esta comprensión los puede liberar de las presiones y de los conflictos conyugales. Sólo la comprensión de la mujer puede resolver positivamente el dilema, sólo con ella pueden aspirar a vivir relativamente tranquilos. Y esto implica que no se les recuerde, a cada momento, su culpa, que no se hurgue en la "herida oculta de la clase obrera", perífrasis utilizada por Sennett en clara alusión al sentimiento de vergüenza. Jamás indican explícitamente qué es aquello que sus mujeres deben comprender, pero la comprensión está siempre presente como única forma de contener las demandas, las quejas y el hastío de su mujer. Comprender la situación es, nosotros sí podemos decirlo, comprenderles a ellos, comprender sus circunstancias, comprender su imposibilidad de mejorar las oportunidades vitales, comprender su bajo estatus social, comprender que están atrapados en la situación en la que se encuentran, y comprender que es por su causa. Por eso la vergüenza asoma en todas y cada una de las ocasiones en que se pronuncia la palabra "comprender". Si la mujer comprende, entonces, puede querer al marido más allá de su estricta circunstancia laboral. Si la mujer no lo comprende, la mujer se hastía y el hombre se avergüenza, contraste emocional que conforma la tercera gran asimetría existente entre los cónyuges. Esta es la clave de la insistencia y de la necesidad de comprensión de estos trabajadores. El problema es, como puede leerse en un extracto, que es más fácil que comprenda un padre a que comprenda una mujer. El padre no arriesga nada, pero para la mujer está en juego su vida y su matrimonio.

\section{Comprensión}

[53] - No, por eso, por otra razón, por los horarios también, por los horarios también. A veces también lo que sucede es que si tu mujer comprende o conoce la hostelería $y$ 
RIS

REVISTA INTERNACIONAL DE SOCIOLOGIA

los horarios pues igualmente tienes suerte y tal, pero si no lo que está haciendo es aguantando, está aguantando y tú no te das cuenta. (16: 157)

[54] - Hombre, yo qué sé, mi chica y yo pues hemos tenido que ser comprensivos yo con ella porque ella sabía que quería estar conmigo y no podía estar yo con ella y al revés. Ella sabía que yo no podía estar y eso es lo peor. (15: 75)

[55] - Bueno, ... comprensión había, porque claro tiene que haberla si se es pareja. Lo que ocurre que llega un momento en que claro te duele que la persona que está contigo pues tenga que tomarse el dia a su rollo, pues porque tampoco se va a quedar en casa aburrida porque esté trabajando, ¿no? Lo veo también mal. Los celillos también, sabiendo que trabaja, si no es celillos también el malestar que te da que bueno, que tenga que buscarse ..., conocer a alguien ... lo típico .... (15.28)

[56] - Porque a veces lo comprenden y otras veces no quieren comprenderlo. A veces dicen: "bueno, hoy estás de descanso, me tienes que llevar a Alcampo a comprar", y no apetece porque a uno le apetece..., me gusta más irme..., hoy es mi día de descanso, me voy a pescar; "no, tienes que llevarme a Alcampo", y ya discuto. (16:95)

[57] - Mi padre es muy comprensivo conmigo porque él ha estado sufriendo muchos años. Ha estado trabajando desde los catorce años, y en tres días a lo mejor no lo veía, luego lo volvía a ver, lo veía nada más que a la hora de comer, porque entre que tú estás en el colegio y eso, y eso pasa. Pero bueno, tú padre es más comprensivo. Yo, mi padre se ha levantado a veces, y yo todavía estoy en la cama y me está haciendo algo de comer para que cuando me levante no pierda tiempo, sino que lo pueda aprovechar en otra cosa. Y me dice, janda!, toma, vete y ... porqué no te vas, y te tomas esta hora, y te vas a la playa. (16:176)

Pero, ¿comprenden los maridos a sus mujeres? El empleado de hostelería, como ellos mismos señalan, está afectado por una "sobredosis de vida social" derivada del desempeño de las tareas propias de su puesto de trabajo, sobredosis que afecta negativamente a su mujer, inhibiendo el interés del trabajador por el cultivo de las relaciones sociales fuera del trabajo. Al contrario que el marido, la mujer está afectada por la soledad del fin de semana, la peor de las soledades ${ }^{8}$. El empleado de la hostelería está afectado por una actividad laboral interminable y estresante.

\footnotetext{
${ }^{8}$ Dado que el tiempo de fin de semana es tiempo, normativamente establecido, de relación social, la ausencia de relaciones sociales en ese tiempo se vive con mayor intensidad y angustia. En las grandes ciudades muchas personas temen al fin de semana precisamente por este motivo. Al menos el trabajo de los días laborales les provee de algunos contactos sociales. Por este motivo, el fin de semana solitario es propenso a los ensueños y a las motivaciones suicidas.
} 
Al contrario que el marido, la mujer está afectada por el aburrimiento del fin de semana, que es el peor de los aburrimientos ${ }^{9}$. El empleado de la hostelería, por último, está afectado por el agotamiento físico, por el cansancio. Al contrario que el marido, la mujer está afectada por el agotamiento psicológico, por el hastio y por la depresión. En el curso de este contraste la mujer se va deprimiendo y se va "quemando". La soledad, el aburrimiento y el hastío estimulan cada vez más las demandas de la mujer sobre el marido, demandas de tiempo, demandas de ocio, demandas de ayuda, demandas de sexo, demandas de atención hacia ella, y demandas de atención y ayuda en el cuidado de sus hijos. La soledad y el aburrimiento conducen a la mujer por el camino de la depresión o por el camino del enfado y de la ira. Las alternativas que tiene la mujer ante sí son cuatro: adaptarse, aguantarse, quemarse o separarse. Si no se adapta, y tan sólo aguanta la situación, lo más probable será que con el tiempo llegue a deprimirse o quemarse. En este caso, más bien temprano que tarde, lo normal es que emerja un fuerte conflicto, bien se presente en su forma de guerra abierta (conflicto expresivamente manifiesto), bien en su forma de silencioso retraimiento (conflicto expresivamente latente). Dada esta última posibilidad, es probable que muchos maridos no se enteren de los verdaderos sentimientos y de las verdaderas demandas de sus mujeres. En su falta de entendimiento, pueden llegar incluso a sorprenderse por las conductas "irracionales" de sus mujeres. Al final del largo túnel, sin duda, la separación y el divorcio acechan.

\section{Depresión}

[58] - ... y entonces, ¿qué es lo que pasa? son mosqueos, son mosqueos. Y ella sabe lo que yo estoy pasando, estoy más jodido porque encima tengo que trabajar pero ella también se está jodiendo. Yo comprendo que ella se jode, pero claro, yo me cabreo más porque soy el que tiene que trabajar. Y cuando le toca a ella yo me cabreo. Terminas en pelea, al final terminamos peleando. Al final pegarte dos o tres días mosqueado para dos horas que te ves, te empiezas a mosquear hasta que te pasa. $(15: 83)$

[59] - Pero el año pasado ya fue definitivo. Llegó un momento, peleas continuas, peleas, peleas, peleas de voces, de gritos, de que yo ya no aguanto más, que me voy con mi madre, que esto es imposible.

- Eso me suena. (16: 142)

[60] - Me ha afectado en el sentido de que la primera esposa, ya llega un momento que no lo comprendía y llegamos, tuvimos que separarnos. Los hijos estaban ya

\footnotetext{
${ }^{9}$ Dado que el tiempo de fin de semana es tiempo lúdico o de ocio, normativamente establecido, pueden aplicarse idénticos argumentos que en la nota precedente.
} 
RIS

REVISTA INTERNACIONAL DE SOCIOLOGia

№ 38, MAYO-ACOSTO, 2004

EDUARDO BERICAT

mayorcitos, nos separamos por eso, porque no comprendía lo de ... o no es que no lo comprendía, pero habia aguantado ya demasiado, y ya llega un momento que no aguantó más, y ya está.(16: 136)

[61] - No, y otra cosa que pasa, eso, que por ejemplo el hecho de que..., en la hora, por ejemplo, el día que salen los amigos, a la hora que salen los amigos, que es justamente que ya estás trabajando o acabas de trabajar y estás hecho polvo y demás, tu mujer no está trabajando en lo tuyo y no entiende en lo que tú estás metido, y eso a la larga, yo por experiencia personal lleva a depresiones gordas, porque te distancias de los amigos cuando pasan dos, tres, cuatro años, que a lo mejor tú no le das ninguna importancia, porque tú estás en tu dinámica de tu trabajo y demás, y tú llevas, tienes la vida muy liada, ¿no?, porque el trabajo, esto, lo otro, sobre todo un trabajo tan.., no voy a decir que sea poco con otro, pero tan dispar, tan distinto, con tantas cosas tan distintas que te pasan en todo el día, y llegas tú y llegas a tu casa y llegas tan bien, y con muchísima vida social, porque nosotros tenemos sobredosis de vida social, y a los cuatro años te das cuenta de que has perdido el contacto con los amigos y demás, y que tu mujer tiene una depresión de caballo y dices: “ijoder!, ¿y esto, qué pasa aqui?"; y te das cuenta y ahora lo dificil es volver a coger, enganchar con los amigos cuando sabes que el horario no te coincide y que es muy difícil..., por lo menos a mí sí ... (16: 107)

Elizabeth Bott señala que los miembros de familias con roles conyugales conjuntos, es decir, aquéllos cuya norma determina como ideal deseable que el marido y la mujer realicen actividades conjuntas, pensaban que "las relaciones sexuales satisfactorias son muy importantes para la felicidad del matrimonio". Para ellos, "era como si unas relaciones sexuales satisfactorias vinieran a demostrar que todo iba bien en las relaciones comunes, mientras que unas relaciones insatisfactorias indicaban un fracaso en la relación global" (Bott, 1990:123). Ateniéndonos a esta correspondencia entre relación general y relación sexual de la pareja, se incluyen algunos extractos en los que se habló, concisa pero muy expresivamente, de sexo. El hombre llega siempre a la casa cansado, demasiado cansado, y no quiere mas que tumbarse en el sofá, que se vayan todos, y que le dejen en paz. Esto es lo que quiere, pero un casado no lo puede decir. En casa está su mujer. "Eso es lo malo", que no se lo puede decir. Sin embargo, el trabajador está cansado, as que tiene que encontrar un modo de decir que no desea, no puede o no está dispuesto para una relación sexual. El trabajador, en esta situación, sólo concibe la cama para dormir. Pero usar la cama, echarse en la cama, puede implicar evidentes riesgos. Es posible que la mujer vea la cama de otra manera, de una manera, digamos, un poco más sexual. Así que, en esta situación, más vale no tomar riesgos. Mejor echarse en el sofá, símbolo e instrumento de la salvaguarda del descanso masculino sin riesgo de incitación al contacto sexual. 


\section{Sexo}

[62] - Pero vaya, que tiempo no tienes realmente, y cuando lo tienes estás tan cansado que lo único que quieres es dormir realmente, o bueno, o dormir o descansar de otra manera, te tumbas en el sofá y dices: "por favor, que nadie diga nada", iros todos de casa...

- Iros al carajo..., qué coño..., y dejar de dar por saco.

- Eso lo puede decir un soltero, pero un casado no lo puede decir.

- Eso es lo malo.

- Eso lo iba a decir yo ahora, hemos tenido telepatía, porque claro, ¿qué pasa con tu mujer?, ella quiere salir... (15: 1)

[63] - Llega un momento en que tu mejor compañero o compañera es la cama. Tú lîegas y la cama ...

- (Hablan todos a la vez)

- Estás cansado y estás cansado. Estás cansado.

- La cama llega a ser tu mejor compañera, por lo menos para mi muchísimas veces ha sido la cama, en un momento dado hasta donde sea, en el sofá.

- Yo se lo digo a la mía, la cama la veo solo para dormir. (15.18)

[64] - ... yo no tengo casa, mi novia tampoco tiene casa ...

- $E l$ " 600 ", que en el asiento de atrás tenía dos agarraderas de esas, ¿sabes para qué las tenía?, para las piernas.

- ¡Hostia! ... Yo me lo he preguntado. Y la gente antiguamente ¿cómo lo podía hacer en un "600"?.

(Respuestas rápidas y sucesivas)

- Con mucho trabajo.

- Y arte.

- Y con mucha imaginación. (15: 119)

Si las relaciones sexuales constituyen una adecuada representación de las relaciones de pareja, analizando el contenido metafórico del último extracto puede sugerirse una conclusión general. Existe una obvia diferencia entre disponer de una "casa" y disponer de un " 600 " a la hora de mantener relaciones sexuales. En el " 600 " se pueden llegar a tener contactos sexuales, pero entonces todo resulta mucho más complicado. ¿Cómo se puede tener una relación sexual en un "600”?, preguntó alguien. Con mucho trabajo, contestó el primero, con mucho arte, contestó el segundo, y con mucha imaginación, aún contestó un tercero.

Así es, en suma. El trabajador de fin de semana, al menos en la sociedad posmoderna, tiene un " 600 " en vez de una "casa". Puede llegar a mantener unas buenas relaciones con su mujer, pero esto, sin duda, requerirá por parte de ambos cónyuges mucho sacrificio y esfuerzo, mucha imaginación y mucho arte. 


\section{CONCLUSIONES}

Iniciamos el recorrido de nuestra investigación poniendo de manifiesto la paradoja laboral de la sociedad del ocio. En base a esta paradoja, puede sostenerse que la sociedad del ocio encuentra un límite objetivo más allá del cual no podrá desarrollarse. Si para que unos disfruten de su tiempo de ocio otros han de estar trabajando, es obvio que no todos los miembros de una sociedad podrán participar en la misma medida de este tan apreciado bien posmoderno.

La paradoja laboral de la sociedad del ocio constituye un fenómeno estructural que se manifiesta en el ámbito vital de las personas. El modo de vida cotidiano de los trabajadores que se ocupan de producir el ocio para el resto de miembros de la sociedad se ve afectado por una inversión de tiempos. Cuando las demás personas están disfrutando de su tiempo de ocio, ellos han de estar trabajando. A la inversa, cuando ellos pueden disfrutar de su tiempo de ocio, las demás personas están trabajando. Dado que el tiempo social no es un tiempo uniforme e indiferenciado, llevar el paso temporalmente cambiado comporta algunas nefastas consecuencias para la calidad de vida de estos trabajadores.

Puede pensarse que el trabajo de fin de semana es algo "natural" que deriva de imperativos funcionales inexorables. Puede pensarse que son las necesidades de producción las que, al igual que sucede en la agricultura, explican su existencia. Sin embargo, el trabajo de fin de semana en la sociedad posmoderna no deriva de imperativos "naturales", como los que afectan a la agricultura, sino que son el resultado de una determinada organización social del tiempo. La división del tiempo entre trabajo y ocio está inserta en una correlativa división o dualización social. Por tanto, una relación social, y no tanto una necesidad natural, es la verdadera causa de un trabajo de fin de semana que comporta un grave deterioro de la calidad de vida.

Este fundamento social del trabajo de fin de semana se manifiesta también en la distribución o asignación social de las personas concretas a empleos concretos. En igualdad de otras condiciones, según pudo demostrarse en los análisis cuantitativos de la investigación, la probabilidad de trabajar el fin de semana aumenta conforme desciende el estatus social de las personas. Siendo esto así, parece evidente que el trabajo de fin de semana ha de ser algo en sí mismo indeseable. Sería absurdo pensar que quienes cuentan con más recursos, o quienes tienen mayor libertad para definir sus propias opciones, eligieran en contra de sus intereses, dejando pasar la oportunidad de disfrutar de la buenas cosas de la vida.

Podíamos intuir, desde ese preciso momento, que el trabajo de fin de semana es objetivamente indeseable, pero todavía no sabíamos exactamente por qué. Para responder a esta pregunta fue necesario llevar a cabo una investigación cualitativa que mostrara las condiciones de existencia de los trabajadores de fin de semana. Una investigación que mostrara, desde la perspectiva del propio trabajador, las consecuencias vitales y cotidianas que comporta la inversión de los tiempos de 
trabajo y de ocio. Solamente de este modo pudimos ser capaces de ver, operando en vivo, la fuerza del tiempo social. Pudimos comprobar que no es lo mismo, ni para el ocio ni para la relación social, ni para el trabajador ni para su familia, disponer del tiempo libre en cualquier tiempo. Es la naturaleza cualitativa y social del tiempo la que da origen y explica el problema de trabajar los fines de semana.

El ser humano no es un mero organismo biológico, es un ser social. Sin embargo, al menos hasta ahora y en nuestras sociedades, la filosofía del tiempo libre que ha inspirado la estructura moral y normativa de la organización del tiempo de trabajo se ha basado exclusivamente en su naturaleza biológica. $\mathrm{Ha}$ sido y sigue siendo una filosofia del descanso. Se adapta muy bien, por decirlo así, al concepto de "reproducción de la fuerza de trabajo". Esta filosofía parte del supuesto básico de que el trabajador sólo tiene derecho al tiempo libre para descansar, para reponer las fuerzas que le permitan reanudar con nuevas energías el proceso de producción. Desde esta filosofía biológica del descanso, es obvio que cualquier tiempo libre puede cumplir perfectamente su función. El organismo descansa físicamente de la misma manera y con la misma intensidad cualquier día de la semana.

Desde una filosofia del ocio, sin embargo, son otras luces y otras sombras las que conforman la figura del trabajo de fin de semana. Dado que el ocio requiere en gran medida de la relación social, algo que la inversión de tiempos de trabajo y de ocio imposibilita, no resulta ya indiferente al trabajador cuáles son sus días libres. Desde una filosofía del ocio, ha de entenderse que el tiempo libre se compone de dos períodos cuya naturaleza social es radicalmente diferente. El tiempo de descanso, cuya funcionalidad es básicamente biológica, y el tiempo de ocio, cuya funcionalidad es básicamente relacional y lúdica. De ahí que el tiempo libre de las sociedades posmodernas deba organizarse de tal modo que sea capaz de garantizar, y de garantizar a todos, un primer tiempo de descanso y también un segundo tiempo de ocio. Este tiempo de ocio no se caracteriza por ser un mero tiempo de reposición, sino que ha de ser un tiempo lúdico y de actividad, un tiempo de acción libre y de fatiga voluntaria. Cuando el descanso necesita ocupar la totalidad o la mayor parte del tiempo libre, cuando el descanso usurpa el tiempo libre, el ocio termina siendo bien una quimera, bien un deseo imposible.

La filosofía del descanso, característica de la sociedad industrial, sigue inspirando, como decimos, los principios morales básicos sobre los que se asienta la estructura jurídica en torno a la ordenación del tiempo de trabajo y sus límites. Así puede constatarse, por ejemplo, en la directiva 93/104/CE del Consejo de la Unión Europea. El "descanso" sigue siendo el único término con eficacia jurídica. No es extraño, por tanto, que esta directiva justifique el contenido de la ordenación del tiempo de trabajo que regula en virtud de unos objetivos explícitos que la propia ley señala: "elevar el nivel de protección de la seguridad y de la salud de los trabajadores". Esto es, la regulación del tiempo tiene la finalidad de garantizar 
la "seguridad física" y "salud física", aspectos orgánicos y biológicos de la vida del trabajador.

La normativa europea citada se preocupa de limitar la "cantidad de tiempo de trabajo", pero apenas dice nada acerca de "cuándo" se realiza este trabajo. Es cierto que este texto legal hace referencia al trabajo "nocturno", así como al trabajo "por turnos". Pero siempre "considerando que ciertos estudios han demostrado que el organismo humano es especialmente sensible durante la noche a las perturbaciones ambientales, así como a determinadas modalidades penosas de organización del trabajo, y que los períodos largos de trabajo nocturno son perjudiciales para la salud de los trabajadores y pueden poner en peligro su seguridad en el trabajo". Esto es, la importancia del "cuándo" se trabaja remite de nuevo, y exclusivamente, a la seguridad y a la salud física de este "organismo" humano. Nada se dice, por el contrario, que afecte al trabajador en tanto que ser social.

Con el estudio del trabajo de fin de semana hemos querido poner de manifiesto nuevos fenómenos, típicamente posmodernos, que afectan a las condiciones de trabajo y a la calidad de vida de los trabajadores. Realidades laborales y vitales que el actual sistema normativo ni asume, ni tan siquiera considera. Hemos pretendido desvelar algunas consecuencias que la ordenación del tiempo de trabajo tiene para ese "organismo social" que es el ser humano. Consecuencias que determinan negativamente su modo de existencia, y que afectan a su "seguridad relacional" y a su "salud relacional". Por este motivo, una ordenación posmoderna del tiempo de trabajo ha de fundarse, no sólo en una filosofía del descanso biológico, sino también en una filosofía del ocio que permita un adecuado desarrollo humano y social de las personas. Una filosofia del ocio que, más allá del mito, evite la dualización social.

El tiempo puede siempre canjearse por dinero, pero el tiempo es algo más que dinero, es en esencia un lugar social en el que habitamos todos los seres humanos. Quienes trabajan con regularidad durante el tiempo sagrado del fin de semana alteran gravemente tanto su experiencia vital como su calidad de vida. Es por esto que creemos necesario la introducción de límites al trabajo de fin de semana, límites normativos establecidos por la legislación laboral que garanticen a todos los trabajadores de la sociedad del ocio el disfrute equiparable de su tiempo libre.

\section{REFERENCIAS BIBLIOGRÁFICAS}

ADAM, B. (1999), “Cuando el tiempo es dinero”, Sociologia del Trabajo, n 37, pp. 5-39.

ARIÈS, PH. (1987), El niño y la vida familiar en el Antiguo Régimen, Madrid, Taurus.

BERICAT ALASTUEY, E. (1991), "Distritos y nebulosas industriales", Sociología del Trabajo, no 11, pp. 49-66. 
BERICAT ALASTUEY, E. y M. CAMARERO RIOJA (1994), Trabajadoras y trabajos en la Andalucia rural, Sevilla, Instituto Andaluz de la Mujer.

BERICAT ALASTUEY, E. (1994), Sociologia de la movilidad espacial. El sedentarismo nómada, Madrid, CIS.

(1995), Informe sobre la economia social en Andalucia, Sevilla, Junta de Andalucía.

(1999), "Tiempo de trabajo y tiempo de vida en el sector turístico", en R. Quesada (edit.), Tiempo de trabajo: empleo y calidad en la industria turistica, Málaga, Consejo Social de la Universidad de Málaga.

BÖGENHOLD, D. (1992), “Economía «alternativa»? Las respuestas de la Sociología del trabajo”, Sociología del Trabajo, nueva época, $\mathrm{n}^{\circ} 15, \mathrm{pp} .3-29$.

BOTT, E. (1990), Familia y red social, Madrid, Taurus.

BEUKEMA, L. (1996), "Los estudios laborales como ciencia intervencionista", Sociologia del Trabajo, nueva época, $\mathrm{n}^{\circ} 28, \mathrm{pp}$. 75-97.

BONKE, J. (1997), "Cambio social y organización del tiempo en los países escandinavos”, Revista Internacional de Sociologia (RIS), $\mathrm{n}^{\circ} 18$, pp. 99-121.

BOSCH, G. y F. MICHON (1990), "Reducción y flexibilización del tiempo de trabajo", en F. Michon y D. Segrestin, El empleo, la empresa y la sociedad, Madrid, MTSS.

CARABAÑA MORALES, J. y C. GÓMEZ BUENO (1996), Escalas de prestigio profesional, Madrid, CIS.

CASSIRER, E. (1971), Filosofia de las formas simbólicas, México, F.C.E.

CETTE, G. y D. TADDEI (1994), “Temps du travail, modes d'emploi. Vers la semaine de quatre jours?, París, La Découverte.

DURÁN, M. A. (1997), "La investigación sobre uso del tiempo en España: algunas reflexiones metodológicas", Revista Internacional de Sociologia (RIS), $\mathrm{n}^{\circ}$ 18, pp. 163-190.

DURKHEIM, E. (1993), Las formas elementales de la vida religiosa, Madrid, Alianza.

ELCHARDUS, M. (1991), "Flexible men and women. The changing temporal organization of work and culture: an empirical analysis", Social Science Information, $\mathrm{n}^{\circ}$ 30, pp. 701-726.

(1994), "In praise of rigidity: on temporal and cultural flexibility", Social Science Information, $\mathrm{n}^{\circ} 33,3$, pp. 459-477.

ELIAS, N. (1989), Sobre el tiempo, Madrid, F.C.E.

FUNDACIÓN FOESSA (1970), Informe sociológico sobre la situación social de España, Madrid, Euroamérica.

GARRIDO MEDINA, L. y E. GIL CALVO (eds.) (1993), Estrategias familiares, Madrid, Alianza. 


\section{RIS}

GERSHUNY, J. (1987), "Estilo de vida, estructura económica y uso del tiempo", Revista Española de Investigaciones Sociológicas, $\mathrm{n}^{\circ} 38$, pp.163-191.

GERSHUNY, J. y I.D. MILES (1988), La nueva economia de servicios. La transformación del empleo en las sociedades industriales, Madrid, MTSS.

HOCHSCHILD, A.R. (1989), The second shift, Nueva York, Avon.

(1997), Time Bind. When work becomes home \& home becomes work, Nueva York, Metropolitan Books.

HOMS, O. (1990), "La cualificación como rigidez o innovación en la organización del trabajo. El caso hotelero", Sociologia del Trabajo, nº 9, pp.9.

HUFTON, O. (1997), "La investigación europea sobre tiempo y género", Revista Internacional de Sociologia, $\mathrm{n}^{\circ} 18$, pp. 83-98.

IGLESIAS DE USSEL, J. (1987), "El tiempo en la sociedad contemporánea", en VV.AA., Tiempo y sociedad. Estudios en homenaje a Francisco Murillo Ferrol, vol. I, Madrid, CIS. Centro de Estudios Constitucionales.

LANGE, W. DE (1995), "Working time and time resource management", en J. van Ruyssenveldt, R. Huiskamp y J. van Hoof, Comparative industrial and employment relations, Londres, Sage.

LEWIS, D.J. y A.J. WEIGERT (1992), “Estructura y significado del tiempo social”, en R. Ramos Torre, Tiempo y Sociedad, Madrid, CIS.

MARK, S.R. (1977), "Multiples roles and role strain: some notes on human energy, time and commitment", American Sociological Review, Vol. 42, pp. 921-936.

MARRERO RODRÍGUEZ, J. R. (1996), "Semejanzas y diferencias en la producción de bienes y servicios”, en Sociologia del Trabajo, n² 26, pp. 63-80.

MARX, K. (1982), El Capital. Critica de la economia política, Vol I, México, F.C.E..

MEAD, G.H. (1959), The Philosophy of the present, La Salle, Open Court Publishing.

MOORE-EDE, M. (1993), The 24 hour society, Londres, Piatkus.

NOWOTNY, H. (1992), "Estructuración y medición del tiempo: sobre la interrelación entre los instrumentos de medición del tiempo y el tiempo social", en R. Ramos Torre, Tiempo y sociedad, Madrid, CIS.

PINO, DEL, J. y E. BERICAT (1999), Valores sociales de la cultura andaluza, Madrid, C.I.S..

PRIETO, C. y R. RAMOS (1999), "El tiempo de trabajo: entre la competitividad y los tiempos sociales", en F. Miguélez y C. Prieto (dirs.), Las relaciones de empleo en España, Madrid, Siglo XXI. 
PRONOVOST, G. (1989), The sociology of time, monográfico de Current sociology, Vol 37, nº 3. (1998), The sociology of leisure, monográfico de Current sociology, Vol. 46, $\mathrm{n}^{\circ} 3$.

QUESADA SEGURA, R. (ed.) (1999), Tiempo de trabajo: empleo y calidad en la industria turistica, Málaga, Consejo Social de la Universidad de Málaga.

RAMOS TORRE, R. (ed.) (1992), Tiempo y sociedad, Madrid, CIS.

(1997), "La ciencia social en busca del tiempo", Revista Internacional de Sociologia, no 18, pp. 11-37.

SENNETT, R. y J. COBB (1972), The hidden injuries of Class, Nueva York, W. W. Norton \& Company.

SOROKIN, P.A. y R.K. MERTON (1937), "Social time: A Methodological and Functional Analysis", American Journal of Sociology, $\mathrm{n}^{\circ} 42$ (5), pp. 615-629.

TRÍAS, E. (1997), Tratado de la pasión, Madrid, Taurus.

ZERUBAVEL, E. (1981), Hidden Rhythms, Chicago, University of Chicago Press.

(1985), The seven day cycle. The history and meaning of the week, Nueva York, Free Press. 